\title{
PILOT-SCALE TESTS OF HEME AND HEPA DISSOLUTION
}

\section{PROCESS (U)}

and

$+\infty$

$\mathrm{w}^{2}+\mathrm{a}$

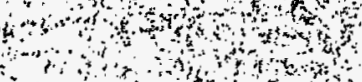

mathond

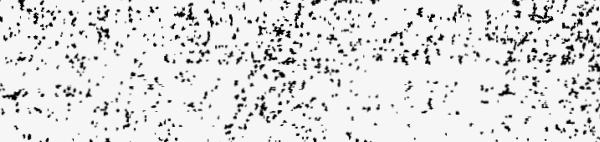

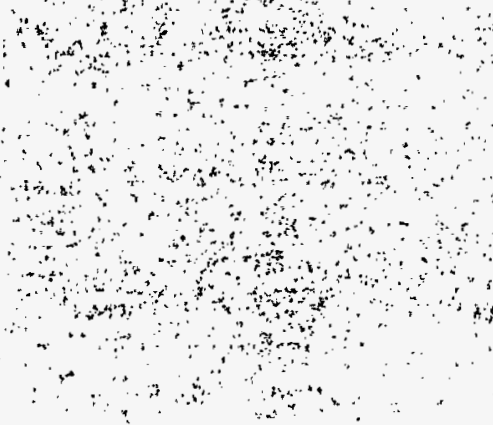

Authors:

Z. H. Qureshi

\section{K. Strege}

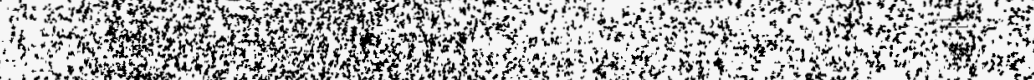

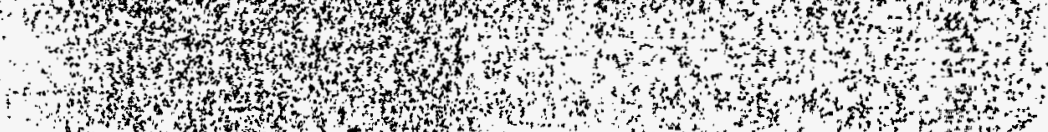

June, 1994 


\section{DISCLAIMER}

This report was prepared as an account of work sponsored by an agency of the United States Government. Neither the United States Government nor any agency thereof, nor any of their employees, makes any warranty, express or implied, or assumes any legal liability or responsibility for the accuracy, completeness, or usefulness of any information, apparatus, product, or process disclosed, or represents that its use would not infringe privately owned rights. Reference herein to any specific commercial product, process, or service by trade name, trademark, manufacturer, or otherwise does not necessarily constitute or imply its endorsement, recommendation, or favoring by the United States Government or any agency thereof. The views and opinions of authors expressed herein do not necessarily state or reflect those of the United States Government or any agency thereof.

This report has been reproduced directly from the best available copy.

Available to DOE and DOE contractors from the Office of Scientific and Technical Information, P.O. Box 62, Oak Ridge, TN 37831; prices available from (615) 576-8401.

Available to the public from the National Technical Information Service, U.S. Department of Commerce, 5285 Port Royal Road, Springfield, VA 22161. 


\section{DISCLAIMER}

Portions of this document may be illegible in electronic image products. Images are produced from the best available original document. 
WSRC-TR-94-0306

KEYWORDS:

HEME/HEPA

FIBERGLASS FILTERS

DISSOLUTION

GLASS C.ORROSION

RETENTION:

PERMANENT

\section{PILOT-SCALE TESTS OF HEME AND HEPA DISSOLUTION PROCESS (U)}

by

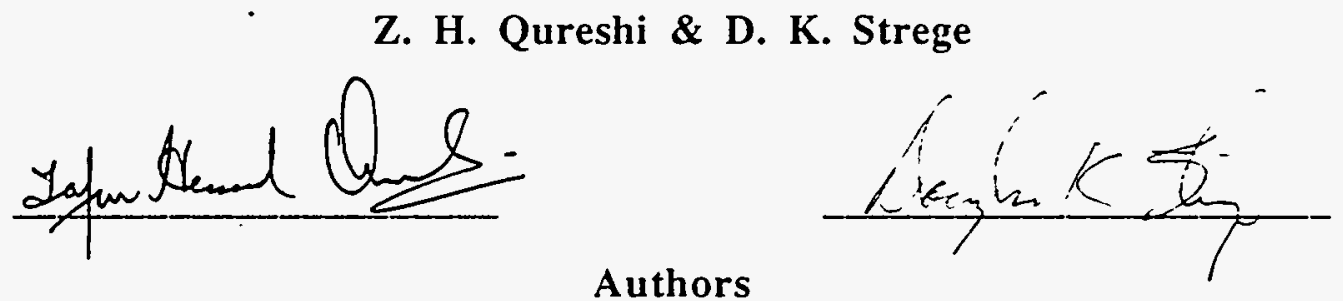

ISSUED: June 1994

SRTC SAVANNAH RIVER TECHNOLOGY CENTER, AIKEN, SC 29808

Westinghouse Savannah River Company

Prepared for the U.S. Department of Energy under

Contract DE-AC()9-89SR $18(1) .35$

iii 
Document: WSRC-TR-94-0306

Title:

TAR NO:

PILOT-SCALE TESTS OF HEME AND HEPA

TAR Date:

DISSOLUTION PROCESS (U)

November 18, 1993.

Activity No: SRT-ETF-TT-93-048

Activity Title: Pilot Scale Demonstration of HEME Dissolution

Process.

Approvals
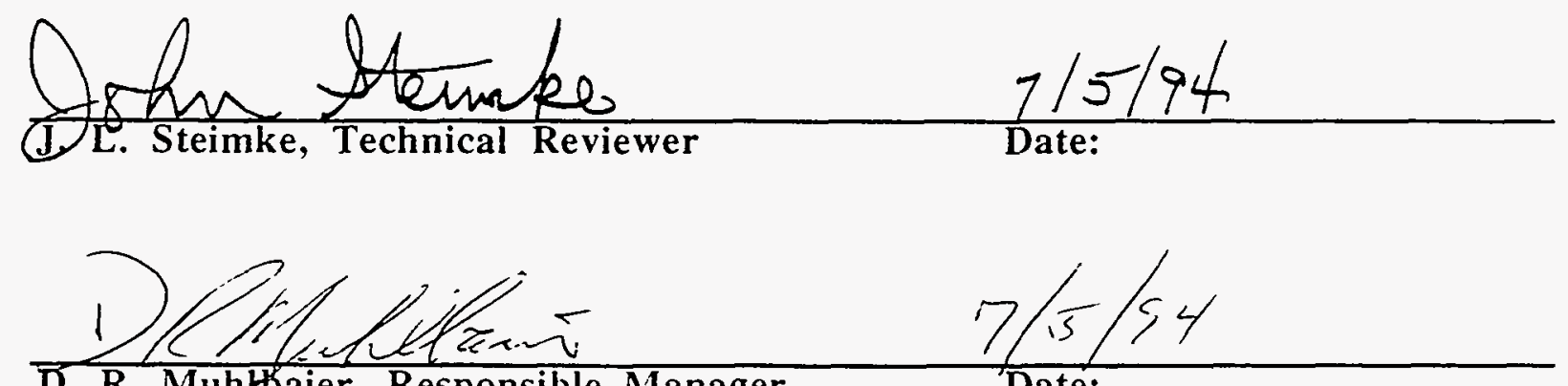

D. R. MuhHaier, Responsible Manager

Date:

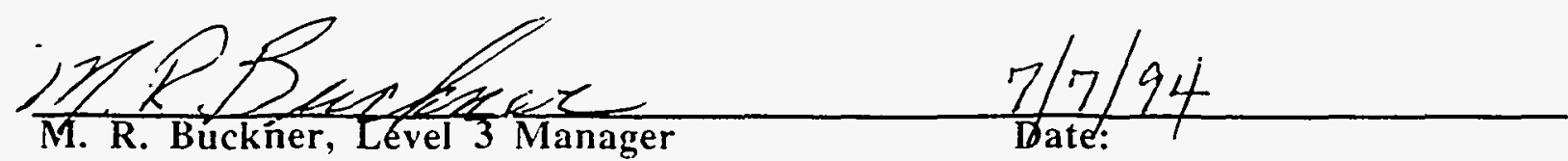




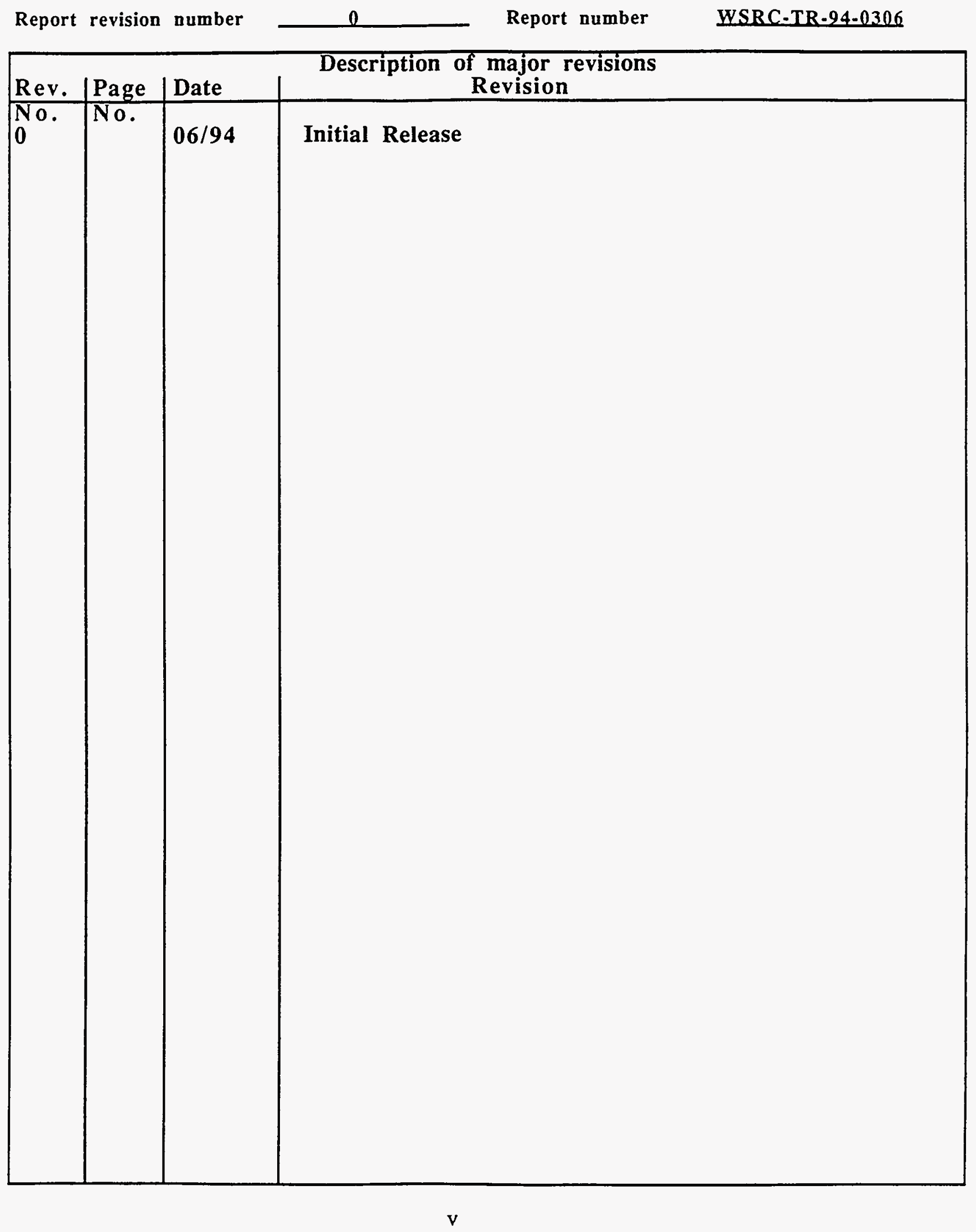




\section{ABSTRACT}

A series of pilot-scale demonstration tests for the dissolution of High Efficiency Mist Eliminators (HEME's) and High Efficiency Particulate Airfilters (HEPA) were performed on a $1 / 5$ th linear scale. These fiberglass filters are to be used in the Defense Waste Processing Facility (DWPF) to decontaminate the effluents from the off-gases generated during the feed preparation process and vitrification. When removed, these filters will be dissolved in the Decontamination Waste Treatment Tank (DWTT) using 5 wt\% NaOH solution. The contaminated fiberglass is converted to an aqueous stream which will be transferred to the waste tanks. The filter metal structure will be rinsed with process water before its disposal as low level solid waste.

As a result of the development of the dissolution process over the last 10 years, the recommended process was a three step process: 48 hours in $5 \mathrm{wt} \% \mathrm{NaOH}, 96$ hours in 5 wt $\% \mathrm{HNO}_{3}$, and 4 hours in $5 \mathrm{wt} \% \mathrm{NaOH}$ at near boiling temperatures. The major issue that led to the three step process is the gelling of the digested fiberglass that would remain trapped in the filter screens.

The pilot-scale study reported here successfully demonstrated a much simpler one step process using $5 \mathrm{wt} \% \mathrm{NaOH}$ solution. The proposed process requires the installation of a new water spray ring with 30 nozzles. In addition to the reduced waste generated, the total process time is reduced to 48 hours only (66\% saving in time). The pilot-scale tests clearly demonstrated that the dissolution process of HEMEs has two stages - chemical digestion of the filter and mechanical erosion of the digested filter. The digestion is achieved by a boiling $5 \mathrm{wt} \%$ caustic solution, whereas the mechanical break down of the digested filter is successfully achieved by spraying process water on the digested filter. An alternate method of breaking down the digested filter by increased air sparging of the solution was found to be marginally successful at best.

The pilot-scale tests also demonstrated that the products of dissolution are easily pumpable by a centrifugal pump. Under the stoichiometrically limiting conditions where $15 \mathrm{HEME}$ filter candles are dissolved in a single batch, the total insoluble solid contents will be about $52 \mathrm{lbm}$ which is less than $0.1 \mathrm{wt} \%$. Thus pumping this mixture does not pose any problem as long as it is agitated and well mixed prior to pumping. 


\section{EXECUTIVE SUMMARY}

This report documents the results of a series of 1/5th pilot-scale demonstration tests for the dissolution of High Efficiency Mist Eliminators (HEME's) and High Efficiency Particulate Airfilters (HEPA). These fiberglass filters are to be used in the Defense Waste Processing Facility (DWPF) to decontaminate the effluents from the off-gases generated during the feed preparation process and vitrification. When removed, these filters will be dissolved in the Decontamination Waste Treatment Tank (DWTT) using $5 \mathrm{wt} \% \mathrm{NaOH}$ solution. The contaminated fiberglass turns into an aqueous stream which will be transferred to the waste tanks. The filter metal structure will be rinsed with process water before its disposal as low level solid waste.

The dissolution process has been under development for the last ten years. Key issues were the determination of the recipe of the dissolver solution(s) and the physical conditions of the process to ensure a complete digestion and breakdown of the filters. All of the previous work was performed on a "beaker scale" using small cubes of fiberglass samples. Prior to the pilot-scale study reported here, the recommended dissolution process was a three step process: 48 hours in $5 \mathrm{wt} \% \mathrm{NaOH}, 96$ hours in $5 \mathrm{wt} \% \mathrm{HNO}_{3}$, and 4 hours in $5 \mathrm{wt} \%$ $\mathrm{NaOH}$ at near boiling temperatures. The major issue that led to the three step process is the gelling of the digested fiberglass that would remain trapped in the filter screens.

As a result of this pilot-scale study, a much simpler one step process using $5 \mathrm{wt} \% \mathrm{NaOH}$ solution is successfully demonstrated. In addition to the reduced waste generated, the total process time is reduced to 48 hours (66\% saving in time). Major objectives of this study were to determine physical conditions that ensure chemical digestion as well as the mechanical breakup of the filter. In order to achieve these, the Experimental Thermal-Fluids Group designed, fabricated and operated a pilot scale (1/5th linear scale, $1 / 125$ th volume) facility and performed 18 dissolution tests. This report provides the specifications and operation of the test facility, test results and recommendation of a dissolution process.

Major findings of the study are summarized below.

1. The pilot-scale tests clearly demonstrated that the dissolution process of HEMEs has two stages - chemical digestion of the filter and mechanical erosion of the digested filter. The digestion is achieved by a boiling $5 \mathrm{wt} \%$ caustic solution, whereas the mechanical breakdown of the digested filter can be achieved by either a high level of solution agitation induced by high air sparge rates or by spraying process water. The first eight tests employed high levels of air sparging for filter breakdown. This was found to be a marginally successful process at best. The last nine tests used the water spray technique which proved to be a definitive technique to wash out the digested filter. A new process water spray ring with 30 spray nozzles is proposed to be added to the DWTT coil assembly. Most of the tests used clean fiberglass supplied by the HEME filter manufacturer. One HEPA dissolution test and two fouled HEME fiberglass dissolution tests required less time for dissolution.

2. A given solution batch can dissolve many HEME/HEPA filters. On a stoichiometric basis, a 6350 gallon $5 \mathrm{wt} \% \mathrm{NaOH}$ solution batch in DWTT has enough $\mathrm{NaOH}$ to dissolve about 15 HEME filter candles (each containing about 115 pounds of fiberglass). The test program demonstrated that at least 7 HEME filters can be dissolved. Considering the total mass of HEPA fiberglass, twice as many HEPAs can be dissolved. 
3. The products of dissolution are easily pumpable by a centrifugal pump. A chemical balance shows that the total amount of insoluble solid contents produced as a result of dissolving each 115 pound HEME candle in DWTT is estimated to be 3.45 pounds. Under the limiting conditions where 15 HEME candles are dissolved in a single batch, the total sludge will be about $52 \mathrm{lbm}$ which is less than $0.1 \mathrm{wt} \%$. Thus pumping this mixture does not pose any problem as long as the mixture is agitated and well mixed prior to pumping.

4. The recommended dissolution process for DWTT operation is to immerse the filter in boiling and sparged ( $20 \mathrm{cfm}$ air) caustic solution for 24 hours to completely digest the outer rope fiberglass layer. Using the proposed water spray ring, wash away the digested rope fiberglass in about 15 minutes by lifting the filter past the ring. Repeat the 24 hour immersion step followed by a 15 minute spraying step to remove the inner layer of mat fiber.

5. The proposed process requires the installation of a new water spray ring with 30 nozzles. The new ring must be completely characterized for its hydraulic performance prior to its installation. 


\section{CONTENTS}

\subsection{INTRODUCTION}

1.1 Background Information

1.2 Objectives of the Pilot-Scale Test Program

1.3 Prior Dissolution Tests

1.4 Glass Dissolution Mechanisms

1.4.1 Interdiffusion

1.4.2 Matrix Dissolution

1.5 Parameters That Influence Glass Corrosion

1.5.1 Glass Composition

1.5.2 Leachant Chemistry and $\mathrm{pH}$ Value

1.5.3 Glass Surface Area to Solution Volume Ratio

1.5.4 Temperature

1.5.5 Rate of Solution Replenishment

\subsection{DISCUSSION}

2.1 Pilot-Scale Facility Design and Description

2.2 Facility Operation and Test Procedures

2.3 Summary of Procedure Performing Dissolution Tests

2.4 Test Matrix

2.5 Results

2.5.1 Test \# 1

2.5.2 Test \# 2

2.5.3 Test \# 3

2.5.4 Test \# 4

2.5.5 Test \# 5

2.5.6 Test \# 6

2.5.7 Test \# 7

2.5.8 Test \# 8

2.5 .9 Test \# 9

2.5.10 Test \# 10

2.5.11 Test \# 11

2.5.12 Test \# 12

2.5.13 Test \# 13

2.5.14 Test \# 14

2.5.15 Test \# 15

2.5.16 Test \# 16

2.5.17 Test \# 17

2.5.18 Test \# 18

2.5.19 Solution Sample Analyses

$\begin{array}{ll}3.0 \text { CONCLUSIONS } & 19\end{array}$

$\begin{array}{ll}4.0 \text { REFERENCES } & 22\end{array}$

$\begin{array}{lr}\text { APPENDIX A } & 23\end{array}$ 


\section{LIST OF FIGURES}

1 Schematic of Pilot-Scale HEME/HEPA Dissolution Test Facility 7

2 Summary of Dissolution Test Conditions and Results 12

3 Proposed Concept for the Additional Spray Ring to Wash 21 Out the Digested Filter

\section{LIST OF TABLES}

1 HEPA Filter Composition 3

2 HEME Filter Composition 4

3 Design Parameters for Full Scale and Pilot-Scale Processes 6

4 Test Conditions for HEME/HEPA Dissolution Tests 10

5 Calculated Amounts of Clean and Fouled HEME Dissolution 18 Products (for $100 \mathrm{lbm}$ of glass dissolved)

6 Results of Solution Samples Analyses 


\section{ACKNOWLEDGMENTS}

Several members of the Experimental Thermal Fluids Group provided excellent and timely support to the program. J. Corbett and T. Steeper provided prompt design support throughout the program. J. Steimke and D. Muhlbaier provided superior technical guidance during conceptual design and in reviewing the program throughout its course. J. Mills skillfully assembled and modified the facility hardware as needed. $\mathrm{K}$. Rohleder and V. Bush are acknowledged for their support for instrumentation, calibration and setting up the data acquisition system. A lot of useful information on glass corrosion provided by $\mathrm{C}$. Cicero, C. Jantzen and G. Wicks is gratefully acknowledged.

Our customers, L. Landon and C. Nash provided prompt responses to many questions and issues related to the test program. Their suggestions were very beneficial to the test program. M. Bennett provided many source drawings and information about the DWTT operations. 
(this page is intentionally left blank)

xii 


\section{INTRODUCTION}

\subsection{Background Information}

High Efficiency Mist Eliminators (HEME's) and High Efficiency Particulate Airfilters (HEPA) are to be used in the Defense Waste Processing Facility (DWPF) to decontaminate the effluents from the off-gases generated during the feed preparation process and vitrification. When removed, these filters are projected to contain sufficient radioactive contaminants to classify them as high level waste and accordingly are not candidates for disposal (burial) on the existing SRS solid waste storage site. Hence, an alternative disposal method of dissolving them with caustic solutions has been proposed. Dissolution converts the waste into an aqueous stream which will be transferred to the waste tanks. The dissolution will take place in the Decontamination Waste Treatment Tank (DWTT).

The mist eliminator in the off-gas stream contains three filter candles, each about $2 \mathrm{ft}$ diameter and $7 \mathrm{ft}$ long. Thus a multiple of three filter candles will be dissolved at a given time. The filters will be placed in a basket (only one HEME candle, or several HEPAs at a time) which will be immersed in caustic solution. The caustic solution will be heated to boiling conditions using the steam coils in the DWTT. An air sparger ring - an integral part of the steam coil assembly, will be used to produce agitation in the tank to facilitate the dissolution process. Once the filter matrix (fiberglass) is dissolved and the products of dissolution are removed from the filter screens, the filter screens and other filter candle hardware will be washed using the water spray ring attached at the top of the steam coil assembly. The washed hardware will be disposed of as low level solid waste. The dissolution process is an off-line process which will be performed as needed, perhaps no frequent than every two years.

\subsection{Objectives of the Pilot-Scale Test Program}

The main objective of the pilot-scale tests reported here was to develop and demonstrate a successful dissolution process to achieve the above waste disposal objectives. This involves both the chemical breakdown (digestion) of the filter fiberglass and the mechanical breakdown of the digested fiberglass to the point where it comes out of the filter screens. The first objective of chemical breakdown was to be achieved by having the proper solution chemistry that can effectively break down fiberglass. The second objective of the mechanical disintegration of the digested fiberglass was to be achieved by testing various methods of agitating the solution or by other mechanical means that can be employed with minimal plant hardware modifications.

\subsection{Prior Dissolution Tests}

Several test tube or bench scale studies of the dissolution process were made between 1984 and 1993 and yielded results with mixed success. Jantzen (1989) summarized the unpublished work of Bransford (1984) and Daugherty (1984) at SRS on HEME/HEPA dissolution process. Daugherty's test were performed by dissolving 66 - 90 grams of fiberglass in a 2 liter $\mathrm{NaOH}$ solution of 5-50 wt \% concentrations. Bransford contracted Environmental and Chemical services (ECS) of New Ellington to dissolve 3"x3"x3" cubes of 8-12 $\mu \mathrm{m}$ HEME filter media in 1 - $5 \mathrm{wt} \% \mathrm{NaOH}$ solution. Based upon these tests Jantzen recommended a three step dissolution process: 48 hours in $5 \mathrm{wt} \% \mathrm{NaOH}, 96$ hours in $5 \mathrm{wt} \% \mathrm{HNO}$, and 4 hours in 5 wt $\% \mathrm{NaOH}$ at near boiling temperatures. Furthermore a demonstration of the scale up dissolution process was recommended. Similar recommendations of a three step process and a large scale demonstration were also made by Cicero (1992).

Major issue identified in these studies is the 'gelling' of the digested filter which was not dislodged from the filter screens by continued immersion of the filter in boiling caustic 
solution. Some tests identified air sparging to enhance agitation of the boiling solution but no systematic scaling was done to accurately simulate air sparging induced agitation of the solution. Under certain conditions, the 'digested' filter samples (typically 1" to 3 " cubes) turn into a gel which does not come out of the filter metal screen. Thus it is important to determine physical conditions that ensure mechanical breakup as well as chemical digestion of the filter. In order to achieve these objectives the Experimental Thermal-Fluids Group undertook the task of developing and demonstrating a successful process on a pilot scale (1/5th linear scale, $1 / 125$ th volume). This report documents these pilot scale tests and results.

Before presenting the pilot scale facility design and the test results, it is important to review the glass dissolution mechanisms as well as the parameters that influence the dissolution process. This provides the basis for the process scaling and the facility design. This is given in the following sections.

\subsection{Glass Dissolution Mechanisms}

A significant amount of glass dissolution literature is available under "glass corrosion" (see Clark et al., 1979). However, most of the literature deals with corrosion of glass slabs or spheres. The literature on glass fibers dissolution is very scarce. Nevertheless, the glass corrosion mechanisms in aqueous solutions are well described in the available literature and they should apply to the fibrous glass also.

Corrosion of simple glasses are commonly considered a two stage process while corrosion of more complex glasses, such as waste glasses, can add an additional step, thus creating a threestage corrosion process. For the present application of dissolving fiberglass in 5\%wt caustic solution at near boiling conditions, the corrosion process is essentially a two-stage process where the second stage is predominant for solution $\mathrm{pH}>9$. These are:

\subsubsection{Interdiffusion}

Interdifussional processes dominate during the early stages of glass corrosion. Potential leachants diffuse into the random network structure of the glass and ion-exchange with alkali and alkali-earth components. This produces an alkali-deficient gel-like layer on the glass surface. This is ideally diffusion controlled and the corrosion rate is proportional to the square root of time.

\section{i.4.2 Matrix Dissolution}

As alkalis are released to solution, the solution $\mathrm{pH}$ rises and dominates glass dissolution. For silica-based glasses, the primary $\mathrm{Si}-\mathrm{O}$ bonds can be attacked at higher $\mathrm{pH}$ values and the glass corrodes congruently (planes of glass dissolving). For systems in which silica concentration in solution is below saturation levels, as in the present application, glass corrosion rate will be relatively constant with time. As mentioned above this mechanism is predominant for $\mathrm{pH}>9$ (for the present application the $\mathrm{pH}$ stays near 14).

\subsection{Parameters That Influence Glass Corrosion}

The glass corrosion or dissolution process is influenced by many parameters. In a scale model of the dissolution process it is important to preserve these parameters or the dimensionless groups formed by the parameters. Key parameters and the associated scaling considerations are described below. 


\subsubsection{Glass Composition}

The chemical durability is greatly affected by the glass composition. For the present application, the fiberglass compositions are known and given by Cicero (1992) for both clean and organically fouled HEMEs and HEPAs. The compositions are reproduced here as Table 1 and Table 2 for HEPA and HEME filters, respectively. For the pilot-scale tests both clean (from the vendor, Monsanto EnvironChem) and organically fouled fiberglass (from the IDMS facility) were used for the HEME tests. A new HEPA filter by Flanders Filters Inc. was also tested. Thus no scaling issue on glass composition arises.

Table 1. HEPA Filter Composition

\begin{tabular}{|c|c|c|c|}
\hline Oxides & $\begin{array}{c}\text { Flanders } \\
\text { Comp. (wt \%) }\end{array}$ & $\begin{array}{c}\text { Clean } \\
\text { Filter (wt \%) }\end{array}$ & $\begin{array}{c}\text { Fouled } \\
\text { Filter (wt \%) }\end{array}$ \\
\hline $\begin{array}{l}\mathrm{Al}_{2} \mathrm{O}_{3} \\
\mathrm{~B}_{2} \mathrm{O}_{3} \\
\mathrm{BaO} \\
\mathrm{CaO} \\
\mathrm{Cr}_{2} \mathrm{O}_{3} \\
\mathrm{Fe}_{2} \mathrm{O}_{3} \\
\mathrm{~K}_{2} \mathrm{O} \\
\mathrm{Li}_{2} \mathrm{O} \\
\mathrm{MgO} \mathrm{Na}_{2} \mathrm{O} \\
\mathrm{NiO}_{2} \\
\mathrm{SiO}_{2} \\
\mathrm{ZnO}\end{array}$ & $\begin{array}{c}5.0-7.0 \\
9.0-11.0 \\
2.5-5.5 \\
2.0-4.0 \\
0.0-0.3 \\
1.5-3.0 \\
0.0-2.0 \\
10.0-12.0 \\
57.0-63.0 \\
0.0-4.5\end{array}$ & $\begin{array}{r}5.282 \\
8.745 \\
3.412 \\
1.100 \\
<0.006 \\
<0.003 \\
2.344 \\
0.038 \\
0.776 \\
9.938 \\
<0.006 \\
57.438 \\
2.882\end{array}$ & $\begin{array}{r}4.439 \\
8.039 \\
3.712 \\
0.809 \\
0.802 \\
2.422 \\
3.446 \\
0.225 \\
0.310 \\
10.789 \\
0.472 \\
46.089 \\
2.800\end{array}$ \\
\hline \multicolumn{4}{|c|}{ Other Species } \\
\hline $\begin{array}{l}\mathrm{H}_{2} \mathrm{O} \\
\mathrm{Hg} \\
\mathrm{Cl} \\
\mathrm{F} \\
\mathrm{F}_{2} \\
\mathrm{NO}_{3} \\
\mathrm{SO}_{4}\end{array}$ & $0.0-0.8$ & $\begin{array}{l}4.697 \\
0.000 \\
0.151 \\
0.656 \\
1.311 \\
0.519 \\
0.614\end{array}$ & $\begin{array}{l}5.308 \\
0.061 \\
0.507 \\
0.678 \\
1.356 \\
6.678 \\
1.058\end{array}$ \\
\hline Totals & & 100.002 & 100.000 \\
\hline
\end{tabular}

\subsubsection{Leachant Chemistry and $p H$ Value}

Based upon prior dissolution tests, it is known that a $5 \mathrm{wt} \% \mathrm{NaOH}$ aqueous solution ( $\mathrm{pH}=14$ ) is most effective in dissolving fiberglass (Daugherty, 1984). All the pilot-scale tests reported here used a $5 \mathrm{wt} \% \mathrm{NaOH}$ solution. As glass dissolves, the solution chemistry changes and as long as the silica concentration remains below saturation levels, the dissolution rate remains constant. Solution $\mathrm{pH}$ is probably the single most important parameter affecting glass corrosion. It is well known that glass corrosion rate is minimum around $\mathrm{pH}$ of 7 and it 
Table 2. HEME Filter Composition

\begin{tabular}{|lcc|}
\hline Oxides & $\begin{array}{c}\text { Clean } \\
\text { Filter (wt\%) }\end{array}$ & $\begin{array}{c}\text { Fouled } \\
\text { Filter (wt\%) }\end{array}$ \\
\hline & 3.972 & \\
$\mathrm{Al}_{2} \mathrm{O}_{3}$ & 4.859 & 4.358 \\
$\mathrm{~B}_{2} \mathrm{O}_{3}$ & 0.208 & 5.424 \\
$\mathrm{BaO}$ & 2.096 & 0.295 \\
$\mathrm{CaO}$ & 0.920 & 2.033 \\
$\mathrm{~K}_{2} \mathrm{O}$ & 0.037 & 0.685 \\
$\mathrm{~L} 2 \mathrm{O}$ & 2.995 & 0.019 \\
$\mathrm{MgO}$ & 18.510 & 3.075 \\
$\mathrm{Na} 2$ & 63.771 & 15.392 \\
$\mathrm{SiO}_{2}$ & 0.013 & 63.502 \\
$\mathrm{ZnO}$ & & 0.007 \\
& & \\
Other Species & & \\
& & \\
$\mathrm{H}_{2} \mathrm{O}$ & 2.120 & 2.950 \\
$\mathrm{Hg}$ & 0.000 & 0.056 \\
$\mathrm{Cl}$ & 0.225 & 0.267 \\
$\mathrm{~F}$ & 0.048 & 0.031 \\
$\mathrm{NO}$ & $<0.300$ & 2.578 \\
$\mathrm{SO}_{4}$ & 0.195 & 0.182 \\
$\mathrm{Totals}$ & 99.999 & 99.999 \\
\hline
\end{tabular}

increases dramatically both in the acidic and basic ranges. During all the tests the solution $\mathrm{pH}$ value remained close to 14 .

It is anticipated that upon removal from service, several HEMEs and HEPAs will be dissolved successively in the DWTT. Thus it is important to simulate the solution chemistry at successive stages. A minimum of about 6350 gallons of solution is needed to ensure complete immersion of the steam coils in the DWTT. Each HEME (84" long, 24" OD and 18" ID) has about 115 pounds of fiberglass. A chemical balance shows that 6350 gallons of $5 \%$ caustic solution can dissolve about 15 HEMEs on stoichiometric basis (Nash, 1993). However, with successive dissolutions, the solution chemistry 'deteriorates' and the last dissolutions may take an unacceptably long time.

Initially, the ratio of solution mass to fiberglass mass is 484 . With successive dissolutions in the same solution batch this ratio decreases. The dissolution tests were conducted with the same initial solution mass to fiberglass mass ratio of 484 . The $1 / 5$ th scale facility used 50.8 gallons of solution (1/125 of 6350) for each batch. The corresponding fiberglass mass is 0.924 lb. As reported later, seven mockup filters were dissolved in a single solution batch without any solution chemistry deterioration.

\subsubsection{Glass Surface Area to Solution Volume Ratio (SA/V)}

For a given solution volume and mass of glass, the dissolution rate is affected by the glass surface area exposed to the solution. Many studies reported in the literature use powdered glass for dissolution studies and higher values of surface area to solution volume ratio resulted in higher dissolution rates. For the present application where glass fibers are to be dissolved, the 
fiber diameter becomes the characteristic dimension that affects dissolution. Two different fiber sizes are used in HEMEs. The inner layer is $1 / 2^{\prime \prime}$ thick $25-35$ micron fiberglass mat and the outer layer is a 2.5" thick 7-12 micron mat. As expected, the 25-35 micron mat took longer to dissolve. The reported tests used both fiber sizes.

The recent fiberglass dissolution tests conducted by Cicero (1992) used the surface areas of the fiberglass sample cubes to compute the SA/V ratio. For example a one inch cube sample yields a surface area of 6 sq. inches. Due to high porosity (about 90\%) of fiberglass the surface area based upon individual fibers is more appropriate for simulation purposes. Thus to preserve SA/V parameter (based on the actual fiber surface area) in the pilot-scale tests, the ratio of fiberglass mass to the solution must was preserved along with the fiber diameter. Thus each test dissolved $0.924 \mathrm{lb}$ of fiberglass shaped into a cylindrical form of different thicknesses in the range $0.6^{\prime \prime}$ to $2 "$.

\subsubsection{Temperature}

The previously mentioned studies document the increase in glass corrosion rates with the solution temperature. However, interpolation of the data obtained in the region of $100^{\circ} \mathrm{C}$ may become difficult (Clark et al., 1979). It has been found that the effective corrosion rate of glass powders measured at the boiling temperature $\left(\sim 100^{\circ} \mathrm{C}\right)$ is much greater that expected based on data obtained at lower temperatures in which no ebullition occurs. The reason for this is that during ebullition, breakdown will occur of any aggregates of grains present in the sample, thus effectively increasing SA/V ratio. Additionally, the boiling process enhances the mass transfer rates from the glass surfaces.

The recent dissolution studies recommend near boiling conditions during the actual process. All the dissolution tests were conducted over a temperature range of $95-100^{\circ} \mathrm{C}$.

\subsubsection{Rate of Solution Replenishment}

The rate at which the solution is replenished may have significant effect on the fiberglass dissolution and breakup. For planar glass slabs in high $\mathrm{pH}$ solution, the dominant corrosion mechanism is the glass matrix dissolution (stage 2 discussed in section 1.4.2), assuming that the glass slab remains in contact with a large solution volume. For the fiberglass, the actual dissolution process will be somewhat different physically, although the dissolution mechanism will be the same. The fiberglass has a porosity of about $90 \%$. Upon immersing this fiberglass in $5 \%$ caustic solution and assuming all the voids are filled with the solution, the amount of $\mathrm{NaOH}$ in the 'soaked' filter can only dissolve about $14 \%$ of the glass on a stoichiometric basis. Whereas, the outer and the inner surfaces of the filter are in contact with bulk of the solution and a complete dissolution occurs from the exposed surfaces inwards. If the solution trapped in the fiberglass is replenished with fresh solution, the entire fiberglass matrix will dissolve and break down effectively.

The solution replenishment can be achieved by very large scale agitation or by pumping fluid through the filter matrix. Solution pumping through the filter matrix was unsuccessful due to the impervious nature of the digested filter and the associated high pressure drop. Some agitation can be achieved by the air sparger in the DWTT. The HEME dissolution operation in the DWTT will not have the agitator (due to the presence of the filter dissolution basket), but the air sparger is available with the steam coils. The sparger is designed to give about $24 \mathrm{cfm}$ of air under operating conditions. The sparger flow rate can be increased to about $56 \mathrm{cfm}$. The first phase of the dissolution tests was done with a scaled down sparger. Scaling of the sparger is guided by preserving the superficial velocity of the sparged air (air flow rate per unit cross section of the tank). Since the cross section of the pilot scale tank is $1 / 25$ th of the DWTT, the air flow rate is to be reduced to $2.24 \mathrm{cfm}$ (1/25 of the maximum DWTT air flow rate). As 
reported later, agitation by air sparging only proved to be a marginally successful process in breaking down the digested filter. Thus a second phase of the test program was completed with an additional step of spraying process water on digested filter raised above the liquid level.

\section{DISCUSSION}

This section provides the design details of the pilot-scale facility, test procedures and results of the 18 dissolution tests performed.

\subsection{Pilot-Scale Facility Design and Description}

Based upon the above scaling arguments and considerations given in section 1.5 , the computed dimensions and parameter ranges for the pilot-scale facility are provided below as Table 3 .

Table 3. Design Parameters for Full Scale and Pilot-Scale Processes.

\begin{tabular}{|lll|}
\hline \multicolumn{1}{|c|}{ Parameter } & \multicolumn{1}{c|}{$\begin{array}{c}\text { Full Scale } \\
\text { Process }\end{array}$} & \multicolumn{1}{c|}{\begin{tabular}{c}
\multicolumn{1}{c|}{ Pilot-Scale } \\
Process
\end{tabular}} \\
\hline 1. Process tank diameter & $12 \mathrm{ft}$ & $28.8 \mathrm{in}$ \\
2. Process tank height & $16 \mathrm{ft}$ & $32.0 \mathrm{in}$ \\
3. Solution volume (5\% caustic) & 6350 gallons & 50.8 gallons \\
4. Solution mass/fiberglass mass & 484 & 484 \\
5. HEME fiberglass mass & $115.5 \mathrm{lbm}$ & $0.924 \mathrm{lbm}$ \\
6. HEME fiberglass volume & $8.25 \mathrm{cubic} \mathrm{ft}$ & $114.0 \mathrm{cubic}$ in \\
7. HEME fiberglass length & $6 \mathrm{ft}$ & $14.4^{\prime \prime}, 8.18^{\prime \prime}, 6.42^{\prime \prime}$ \\
8. HEME fiberglass OD & $2 \mathrm{ft}$ & $4.8^{\prime \prime}, 4.8^{\prime \prime}, 4.8^{\prime \prime}$ \\
9. HEME fiberglass $\mathrm{DD}$ & $1.5^{\prime}$ & $3.6^{\prime \prime}, 2.3^{\prime \prime}, 0.8^{\prime \prime}$ \\
10. HEME fiberglass thickness & $3^{\prime \prime}$ & $0.6^{\prime \prime}, 1.25^{\prime \prime}, 2^{\prime \prime}$ \\
11. NaOH per solution batch & $2800 \mathrm{lbm}$ & $22.4 \mathrm{lbm}$ \\
12. Temperature & $\sim 100^{\circ} \mathrm{C}$ & $95-100^{\circ} \mathrm{C}$ \\
13. Air sparge rates & up to $56 \mathrm{cfm}$ & up to $5 \mathrm{cfm}$ \\
\hline
\end{tabular}

Figure 1 shows the schematic of the Pilot-Scale HEME/HEPA Dissolution Test Facility. Major components are the process tank, steam/cooling coils, an air sparge ring, a centrifugal pump, loop piping, instrumentation and a weighing system for the filter mockups. A stainless steel 


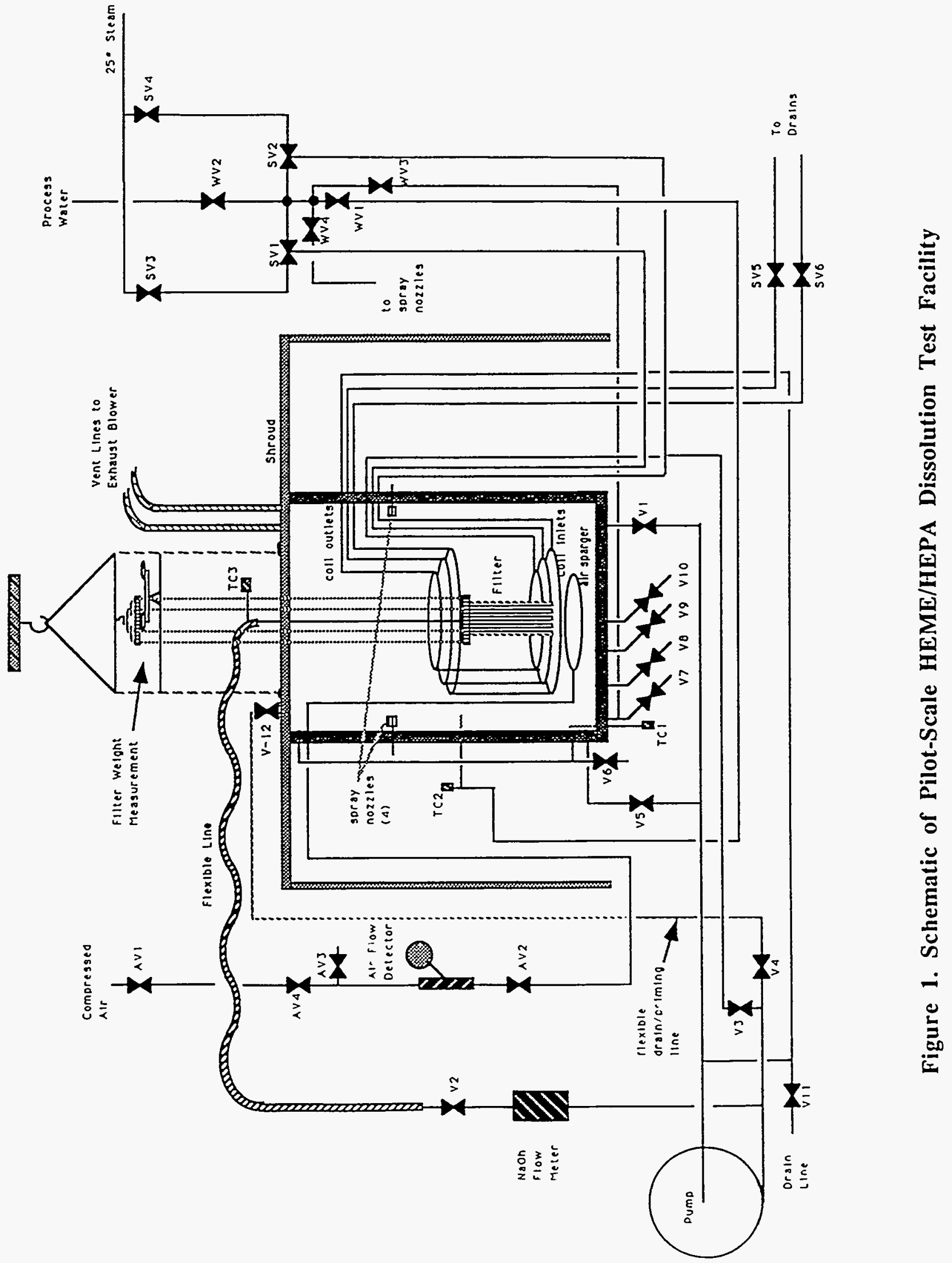


cover with viewing windows was placed on the tank top. A chain hoist was used to lift the cover and the attached plastic shroud for periodic inspection of the filter mockup. The test facility was assembled near the steam generator in the Thermal Fluids Lab of SRTC. The test facility was connected to the steam, process water, compressed air, exhaust vent and floor drains. The entire facility was placed in a secondary stainless steel containment of about 100 gallons capacity in order to contain any accidental spill of caustic solution during the facility operation or solution transfer.

Three thermocouples $\left(0-300^{\circ} \mathrm{C}\right.$ range, $1.7^{\circ} \mathrm{C}$ tolerance) were installed to measure the solution temperature: one $2 "$ above the tank bottom, one $3^{\prime \prime}$ below the liquid surface and one in the inlet manifold of the solution pumping loop. The air sparge rate was measured by Kurz Air Mass Flow Meter ( 0 - $10 \mathrm{cubic}$ feet $/ \mathrm{min}, 0.25 \mathrm{cfm}$ tolerance). The solution flow rate through the pump loop was measured by Fischer \& Porter Magnetic Flow Meter (0 - 30 gpm, tolerance: $1.0 \%$ of reading plus $0.5 \%$ full scale).

The test facility was designed to perform the HEME dissolution tests in two phases. Tests in the first phase were performed using sparged air as means of agitation to break down the digested fiberglass. Since this means of agitation proved to be marginally successful, the second phase of testing included spraying the digested filter with process water. Four stainless steel nozzles (\#5.5, 0.060" orifice diameter, $15^{\circ}$ spray angle) manufactured by Teel were installed $90^{\circ}$ apart around the dissolution tank. The nozzles are $6^{\prime \prime}$ above the solution level and about 12 " away from the filter target. The four nozzles provide $3 \mathrm{gpm}$ flow rate at a supply pressure of 85 psig. The spray field provides a $360^{\circ}$ coverage of the filter cage.

\subsection{Facility Operation and Test Procedures}

A detailed technical procedure was written specifically for the operation of the facility. Details of the procedure are documented as "Operation of Pilot-Scale HEME Dissolution Facility" SRT-ETF-TP-94-004, Rev 0, March 10, 94. It provides procedures for the following operations.

- Operation of Data Acquisition System (DAS).

- Procedure for weighing the filter.

- Procedure for operating the chain hoist.

- Procedure for changing the filter.

- Tank fill-up procedure.

- Air sparger operation.

- Steam coils operation.

- Procedure for preparing the 5 wt $\% \mathrm{NaOH}$ solution.

- Procedure for packing the filter mockup with fiberglass.

- Procedure for performing dissolution tests.

- Procedure for draining the tank. 
Details for the above procedures are omitted here since they are documented as referenced above. However a summary of the procedure for performing dissolution tests is provided below for the sake of completeness of this report.

\subsection{Summary of Procedure for Performing Dissolution Tests}

1. The Task Leader provides the Test Engineer specific written test conditions which are recorded in the lab notebook. The Test Engineer and/or the Technician then perform the test according to the following instructions.

2. Pack the filter mockup with fiberglass as specified.

3. If the DAS is not already on, turn it on and allow about 30 minutes for warm up.

4. Install the mockup filter in the facility following the "Procedure for Changing the Filter".

5. Measure and record in the lab notebook or data sheet all three temperature signals.

6. Lower the tank cover using the "Procedure for Operating Chain Hoist" and record the time when filter is immersed in the solution. This time will be referred to as the "test start time".

7. Measure the weight of the filter under immersed conditions and record it on the lab notebook or the data sheet. Follow "Procedure for Weighing the Filter". Leave the filter hanging loose during the actual dissolution tests.

8. Turn on exhaust blower and air compressors.

9. Heat the tank solution by using the procedure for "Steam Coil Operation".

10. Start air sparging to the level specified in the test conditions provided by the Task Leader.

11. Monitor the solution temperature and record TC-1 and TC-2 at 5 minutes interval. The interval may be changed by Task Leader. If so record in the logbook.

12. Maintain the solution temperature within $\pm 1^{\circ} \mathrm{C}$ of the specified value using TC-2. The tolerance may be changed by Task Leader. If so record in the logbook.

13. Once the temperature remains within the specified range, record it at 5 minutes intervals.

14. After one hour from the test start time stop steam heating and air sparging and wait for 2 minutes for the fluid currents to subside.

15. Draw about $100 \mathrm{ml}$ of solution in a stainless steel beaker. Then draw $10 \mathrm{ml}$ of solution sample in a vial and mark the vial with date, time and sample number. Provide description of the sample in logbook. Pour the $100 \mathrm{ml}$ solution in stainless steel beaker back in the tank using a funnel with a dip tube to avoid splashing.

16. Check the solution level and add $10 \mathrm{ml}$ of solution and make up water as needed.

17. Measure and record the filter weight in logbook.

18. Raise the tank cover by the chain hoist to the height where the filter bottom plate is at the tank top flange level. 
19. Using a flashlight or flood light, observe the entire filter for dissolution/breakdown. Record observations in the notebook. Take photographs if deemed necessary.

20. If filter screens are not completely empty, lower the filter again and continue heating and sparging to the specified levels. Repeat steps 14 to 19 until the filter is fully disintegrated and the screens are empty. The inspection time interval can be varied to another suitable value after consulting with the Task Leader.

21. Upon completion of a dissolution test, shut down the steam generator and bring the solution temperature below $40^{\circ} \mathrm{C}$ using cooling coils. Shut down the DAS. Leave the tank cover resting on the tank flange. Turn off exhaust blower and air compressors.

\subsection{Test Matrix}

A total of 18 dissolution tests (17 with HEME mockups and one with HEPA) were performed. Table 4 below provides the test conditions for all the 18 tests. It is important to note that the entire test matrix was not planned at the beginning of the test program. Instead, only one test at a time was planned and conditions for the subsequent test were chosen based upon the results of the preceding test.

Table 4. Test Conditions for HEME/HEPA Dissolution Tests

\begin{tabular}{|c|c|c|c|c|c|}
\hline Test \# & $\begin{array}{c}\text { *Mockup } \\
\text { No. }\end{array}$ & $\begin{array}{l}\text { Fibergl } \\
\text { Rope (lbm) }\end{array}$ & $\begin{array}{l}\text { ss Mass } \\
\text { Mat (lbm) }\end{array}$ & $\underset{\left({ }^{\circ} \mathrm{C}\right)}{\text { Temp. }}$ & $\begin{array}{l}\text { Solution } \\
\text { Batch No. }\end{array}$ \\
\hline $\begin{array}{r}1 \\
2 \\
3 \\
4 \\
5 \\
6 \\
7 \\
8 \\
9 \\
10 \\
11 \\
12 \\
13 \\
14 \\
15 \\
16 \\
17 \\
18\end{array}$ & $\begin{array}{c}3 \\
3 \\
3 \\
2 \\
3 \\
3 \\
3 \\
1 \\
\text { HEPA } \\
3 \\
2 \\
1 \\
3 \\
2 \\
3 \\
2 \\
3 \\
2\end{array}$ & $\begin{array}{l}0.924 \\
0.924 \\
0.924 \\
0.924 \\
0.924 \\
0.924 \\
0.769 \\
0.924 \\
0.238 \\
0.849 \\
0.820 \\
0.924 \\
0.769 \\
1.036 \\
0.860 \\
0.836 \\
0.825 \\
0.679\end{array}$ & $\begin{array}{c}0 \\
0 \\
0 \\
0 \\
0 \\
0 \\
0.154 \\
0 \\
\\
0.075 \\
0.104 \\
0 \\
0.154 \\
0.099 \\
0.064 \\
0.088 \\
0.099 \\
0.245\end{array}$ & $\begin{array}{r}95 \\
95 \\
95 \\
95 \\
95 \\
95 \\
95 \\
100 \\
100 \\
100 \\
100 \\
100 \\
100 \\
100 \\
100 \\
100 \\
100 \\
100\end{array}$ & $\begin{array}{l}1 \\
1 \\
1 \\
1 \\
2 \\
2 \\
2 \\
3 \\
3 \\
3 \\
3 \\
4 \\
4 \\
4 \\
4 \\
4 \\
4 \\
4\end{array}$ \\
\hline $\begin{array}{c}\text { * Mockup } \\
\text { Mockup \# } \\
1 \\
2 \\
3\end{array}$ & $\begin{array}{c}\text { Dimensions } \\
\text { ID (in) } \\
3.6 \\
2.3 \\
0.8\end{array}$ & $\begin{array}{c}\text { OD (in) } \\
4.8 \\
4.8 \\
4.8\end{array}$ & $\begin{array}{c}\text { Length (in) } \\
14.40 \\
8.18 \\
6.42\end{array}$ & & \\
\hline
\end{tabular}




\subsection{Results}

Through the 18 dissolution tests, the test program met both objectives of chemical digestion and mechanical breakdown of the mockup filters. In the first eight tests air sparging was primarily used as means of agitation required to mechanically break down the digested filter. Additionally, for Test \# 2 \& 3, an attempt was made to pump the solution through the filter fiberglass matrix but due to very high pressure drop across the packed fiberglass, an effective solution pumping was not achieved. Furthermore, once the individual glass fibers develop gel layers, the filter matrix become quite impervious. Thus the caustic solution was not pumped in the subsequent tests. Air sparging was found to be marginally successful process. In particular, for Test \# 7 - the first composite filter, the rope was packed very tightly since the inner mat layer 'sprung' outwards. Consequently, the digested rope remained packed and could not be removed from the screens by $2.24 \mathrm{cfm}$ air sparging (corresponding to plant maximum sparge rate of $56 \mathrm{cfm}$ ). A $100 \%$ increase in air sparging to $4.48 \mathrm{cfm}$ was used to breakdown the filter. Providing higher sparging rates would have resulted in plant hardware modifications. After this test it was decided to pursue more definitive means of breaking down the digested fiberglass for its removal from the mockup screens by using spray nozzles to erode the digested filter.

While different means were being evaluated, Test \# 9 was performed using about 1/2 of an actual HEPA filter. Note that the HEPA fibers are very small and all the prior studies indicated easy dissolution and breakup of HEPAs. This was confirmed by Test \# 9 . In just two hours the HEPA was disintegrated at an air sparge rate of $0.8 \mathrm{cfm}$ (corresponding to plant sparge rate of $20 \mathrm{cfm})$.

Tests 10 through 18 were performed under boiling caustic conditions at a lower sparge rate of $0.8 \mathrm{cfm}$ (corresponding to plant sparge rate of $20 \mathrm{cfm}$ ). Additionally, the filter was periodically raised above the liquid level and sprayed with process water using four spray nozzles (\#5.5, $0.060^{\prime \prime}$ orifice diameter, $15^{\circ}$ spray angle, manufactured by Teel) to remove the digested fiberglass layer. Initially, spraying was done every four hours but from plant operational considerations the spray interval was later increased to 24 hours.

Figure 2 provides the summary of all the 18 tests discussed above. For each test, different test conditions - heating, sparging, unheated soaking and spraying are shown in chronological order. Additionally, estimates of digested filter mass are also provided on the figure. Chronological descriptions for each dissolution test are provided as Appendix A.

A brief discussion of results of each test is given below.

\subsubsection{Test \# 1}

For Test \# 1, Mockup \# 3 (see Table 4 for mockup dimensions) was packed with $0.924 \mathrm{lbm}$ of bulk rope fiberglass. The mockup was placed in 50.8 gallons of $5 \mathrm{wt} \% \mathrm{NaOH}$ solution. The solution was heated to $95^{\circ} \mathrm{C}$ and the air sparge rate was set at $2.24 \mathrm{cfm}$ (corresponding to a plant maximum rate of $56 \mathrm{cfm}$ ). These conditions were maintained for 8 hours and at that time the fiberglass was found to be partly gelled. The heating and sparging was then terminated overnight for 16 hours and the solution temperature dropped to $45^{\circ} \mathrm{C}$. At 24 hours the fiberglass was found to be completely digested and appeared like packed snow. The overall filter geometry remained somewhat intact. At this time the filter had lost its fibrous structure and strength.. Additional 6 hours of heating and sparging eroded the digested filter away and the screens were completely empty at 30 hours. Chronological observations of the test at every two hour interval are given in Appendix A. 


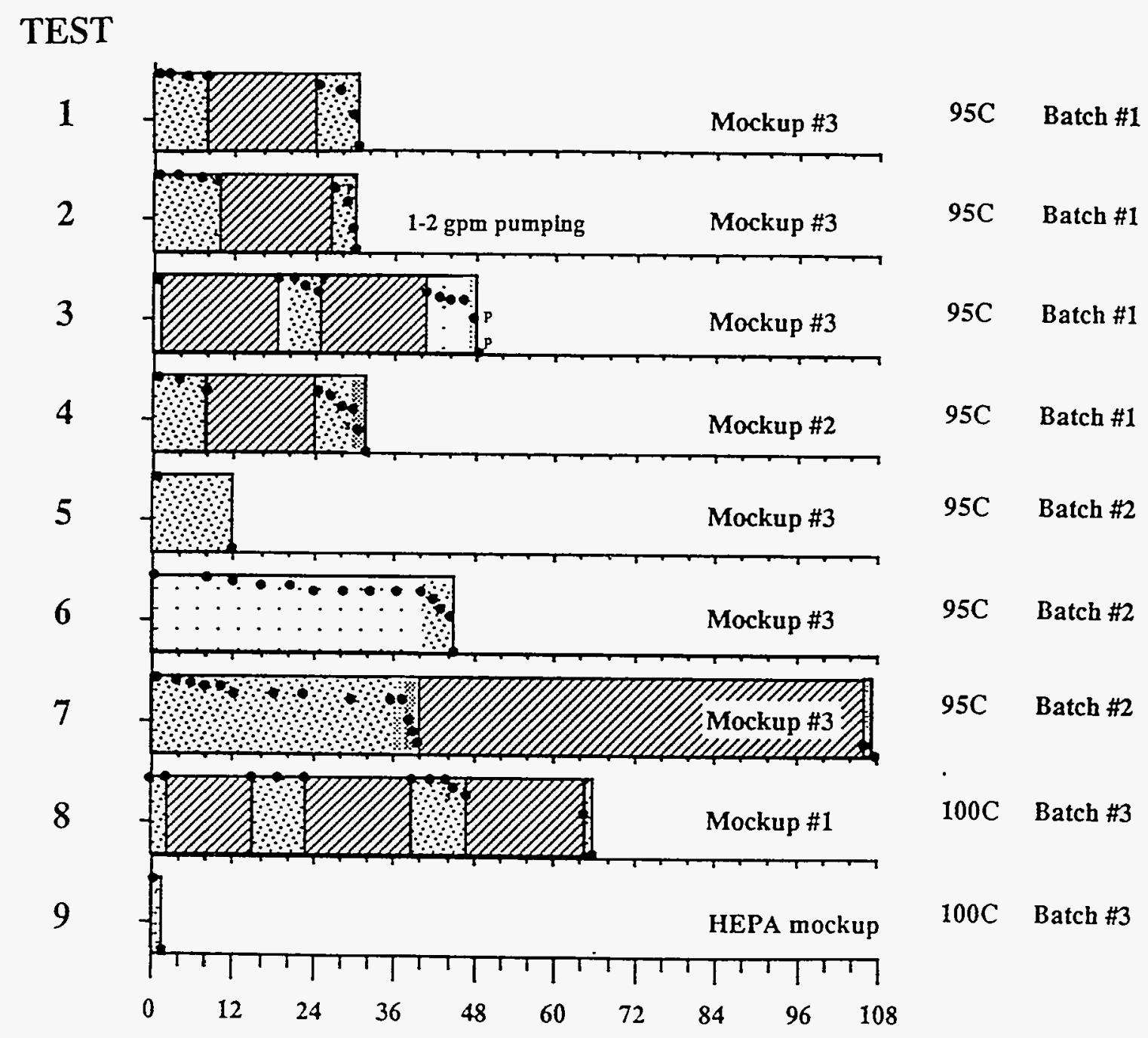

TIME (hours)

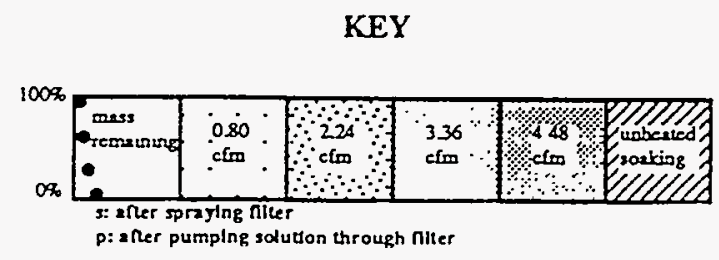

Figure 2. Summary of Dissolution Test Conditions and Results 


\section{TEST}

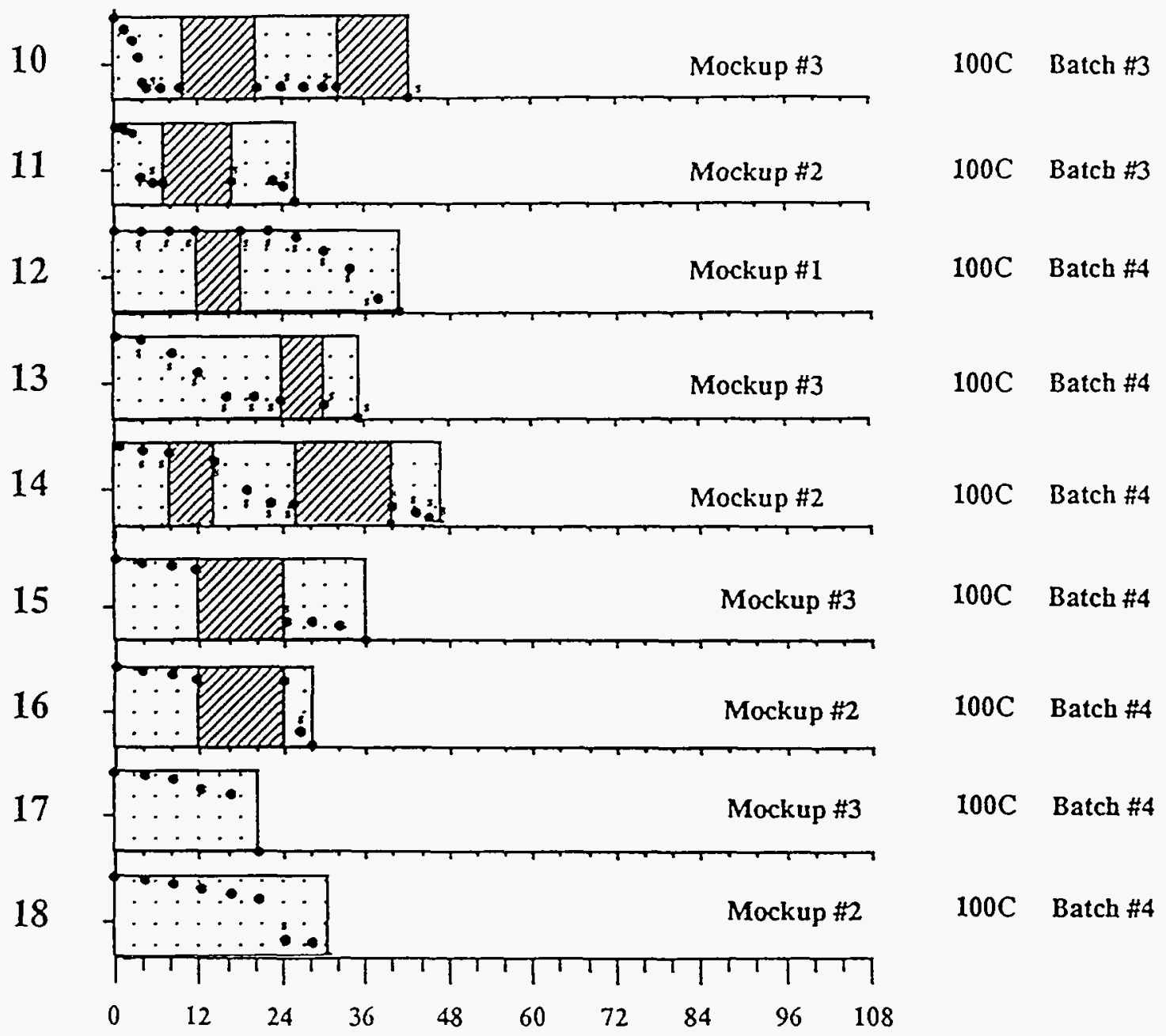

TIME (hours)

KEY

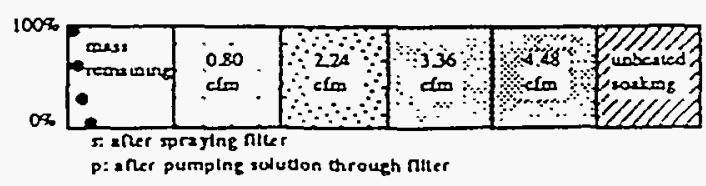

Figure 2 (Contd.) Summary of Dissolution Test Conditions and Results 


\subsubsection{Test \# 2}

Test \#2 was a repeat of Test \#1 with an additional step of pumping 2 gpm solution through the filter fibers. It was anticipated that with solution pumping, the entire fibrous matrix will be exposed to the solution which is continuously replenished, thus accelerating the digestion process and minimizing the filter gelling. However, the filter resistance to liquid flow was found to be very high and effectively no fluid could be pumped during the initial digestion period. Additionally, as the digestion process proceeded, the packed fiberglass became essentially impervious. The overall test results were the same as for Test \#1 and the filter disintegrated completely in about 30 hours.

\subsubsection{Test \# 3}

Test \#3 was also a repeat of Test \#1, but preceded by an initial soaking of the filter in warm caustic solution for about 18 hours. The purpose of this test was to determine the effect of presoaking the filter on the dissolution characteristics. Initially the solution was heated to $95^{\circ} \mathrm{C}$ without any air sparging and after immersing the filter in it, the heating was shut down overnight and consequently the solution temperature dropped to about $45^{\circ} \mathrm{C}$ by next morning. It was observed that due to somewhat low average temperature overnight, the digestion process was not complete and the filter exhibited fibrous structure and strength even after $18 \mathrm{hrs}$ of soaking. For the next 7 hours the solution was kept at $95^{\circ} \mathrm{C}$ with air sparging at $2.24 \mathrm{cfm}$. No noticeable erosion was observed. The heating and sparging was terminated and the filter was left for another soaking period of 16 hours. At 41 hours, the solution was heated again and sparged for 5 hours at $0.96 \mathrm{cfm}$ (corresponding to a plant rate of $24 \mathrm{cfm}$ ). The erosion of the digested filter was very slow. In order to accelerate erosion, the air sparge rate was then increased to $3.36 \mathrm{cfm}$ and held for one hour but it did not accelerate erosion. The filter was fully digested at 41 hours but remained mechanically strong. Finally, 15 minutes of solution pumping at 10 gpm broke away the filter into small chunks by mechanical impact. Comparing to the first two tests, the presoaking of the filter adversely affected both the digestion and the erosion characteristics.

\subsubsection{Test \# 4}

Test \#4 was also a repeat of Test \#1 in the same solution batch \#1, but with mockup \#2. Note that Test \#1 used mockup \#3 where the fiberglass thickness is $2^{\prime \prime}$. Mockup \#2 has $1.25^{\prime \prime}$ thick fiber packing. The purpose of this test was to determine the effect of fiber thickness on the dissolution characteristics. The filter was fully digested at hour 25 . The filter then started eroding by $2.24 \mathrm{cfm}$ sparge rate, but after about 4 hours the erosion rate decreased and about $60 \%$ digested filter mass remained in the screens. The sparge rate was then doubled to 4.48 $\mathrm{cfm}$ which increased erosion rate. It was realized that air sparging may only be a marginally successful process in eroding the filter. In order to find a more definitive erosion process, a 0.6 gpm water stream was sprayed for one minute over the remaining $25 \%$ digested mass which was successful in cutting through it. It took another 1 hour of $4.48 \mathrm{cfm}$ sparging to completely remove the digested fiberglass. The total test time was 31 hours.

\subsubsection{Test \# 5}

Based upon the first four tests it was concluded that overnight soaking of the filter at the beginning or during testing helps gelling the digested mass. It is anticipated that the plant operation will be round the clock and the actual dissolution in DWTT will take place on a continuous basis. Initially the pilot scale facility was not manned round the clock and testing was done only during the normal day shift. It was decided to run a nonstop test. Test \#5 was a repeat of Test \#1 but under continuous heating and sparging conditions. A fresh solution batch \#2 was prepared for Test \#5. The previous four tests took about 30 hours to complete. Test \#5 
was completed only in 12 hours. The first 10 to $11 \mathrm{hrs}$ is the chemical digestion time for the mockup filter. The second phase of mechanical erosion and breakup of the filter took only about an hour.

\subsubsection{Test \# 6}

Test \#6 was also a continuous run but under lower sparge rates of $0.8 \mathrm{cfm}$ (corresponding to $20 \mathrm{cfm}$ of plant sparge rate). Note that the existing plant instrumentation for the DWTT sparger has a range of 0-24 cfm and it was important to determine if a sparge rate in this range can dissolve and disintegrate the filter while operating on a continuous basis. This sparge rate was found to be insufficient to effectively erode and break down the filter even after 40 hours of continuous run. The sparge rate was then increased to $2.24 \mathrm{cfm}$ (corresponding to $56 \mathrm{cfm}$, max. plant sparge rate). At this increased sparge rate it took only three more hours to completely break down the filter. The total test time was 43 hours.

\subsubsection{Test \# 7}

The first 6 tests were performed with only the rope type fiberglass (7-12 micron fiber diameter). Test \#7 used a composite filter, an inner layer of $0.154 \mathrm{lbm}$ of mat fiber (25-35 micron fiber diameter) and $0.769 \mathrm{lbm}$ of rope fiber as the outer layer. The test was conducted under continuous testing mode at $95^{\circ} \mathrm{C}$ and $2.24 \mathrm{cfm}$ sparge rate. The rope fiber was digested in about 12 hours but did not erode significantly for the next 24 hours at $2.24 \mathrm{cfm}$. The digested filter remained somewhat packed. The sparging was then increased to $3.36 \mathrm{cfm}$ for the next $1.5 \mathrm{hr}$ and no significant erosion was observed. The sparge rate was then increased to $4.48 \mathrm{cfm}$ which was found effective in eroding the filter. It is postulated that the rope fiber was packed to a higher density since the inner mat layers (more porous than rope fiber) would "spring outwards" during the packing. This may have contributed to somewhat stronger lump of digested fiberglass which was difficult to erode at $2.24 \mathrm{cfm}$ sparge rate. The mat fiber was not completely digested. It remained like a dense cotton candy even at the end of 40 hours of continuous operation. About $90 \%$ filter was gone after a total of 40 hours of testing. It was then decided to terminate the test and keep the filter soaked in the solution for next two days to determine if the mat fiber breaks down further. After 66 hours (due to a two day weekend) of soaking, all the fibrous structure was completely broken down and the digested fiberglass turned into a lump with a consistency of frozen yogurt. After about one hour of sparging at $4.48 \mathrm{cfm}$ without heating, all the digested filter was eroded away. As expected, the thick mat fiber took much longer (about 40 hours) to be digested as compare to the rope fiber which took about 12 hours for digestion.

\subsubsection{Test \# 8}

For Test \#8, mockup \# 1 (1/5th scale mockup of HEME) was packed with $0.924 \mathrm{lbm}$ of mat fiber. The purpose of the test was to find the digestion and erosion characteristics of the mat fiberglass. The first 6 tests used the rope type fiberglass and the seventh test used a composite filter. Using a new solution batch \#3, Test \#8 was run under heated and sparged conditions $(2.24 \mathrm{cfm})$ only during the normal day shift. Overnight, it was left soaked in the hot solution without any further heating or sparging. The solution was heated to boiling conditions $\left(\sim 100^{\circ} \mathrm{C}\right)$ since it was easy to maintain this temperature. However, due to boiling more makeup water was added to the tank every hour to maintain the desired level. It took about a total of 66 hours to complete the test. Even after 66 hours the fibrous structure was still present, although much weakened. In order to develop a more definitive process of breaking down the filter, some scoping tests were conducted where a high velocity water jet was shot at the filter mass. At about $0.6 \mathrm{gpm}$, a $1 / 16^{\prime \prime} \mathrm{ID}$ tube jet was effective in making a vertical cut through the $0.6^{\prime \prime}$ layer in 3 minutes. A larger jet from an $1 / 8^{\prime \prime} \mathrm{I}$ tube was not effective in penetrating through the layer. The filter mass was then eroded away by air sparging. Based upon these initial 
observations, it was decided to test several spray nozzles to ensure erosion of the digested fiberglass. While the loop was being equipped with the nozzles, it was decided to run a HEPA dissolution test discussed below.

\subsubsection{Test \# 9}

Test \# 9 was the first HEPA dissolution test. A 10.375" high, 4.25" wide and 5.75" deep section of a clean HEPA filter with a prototypical stainless steel frame was prepared by cutting a full size HEPA into about half $(0.238 \mathrm{lbm}$ fiberglass) and the side plate was glued back using RTV to the newly cut boundary to provide prototypic boundaries on all four sides. The fiberglass texture of the HEPAs is much weaker than those of HEMEs. It took about two hours to disintegrate the filter at $100^{\circ} \mathrm{C}$ and at a sparge rate of $0.8 \mathrm{cfm}$. The metal frame was pulled out clean and free of any fiberglass. The available sample of fouled HEPA fiberglass was structurally much weaker than the new one and no problems are anticipated for its dissolution.

\subsubsection{Test \# 10}

Test \# 10 was conducted on a composite packing of mockup \# 3 . The inner $1 / 2$ " layer $(0.075$ $\mathrm{lbm})$ was the new mat type fiberglass and the outer $1.5^{\prime \prime}(0.849 \mathrm{lbm})$ was packed with the fouled rope fiberglass obtained from TNX (IDMS facility). The sparge rate was set at $0.8 \mathrm{cfm}$ (corresponding to plant rate of $20 \mathrm{cfm}$ ). Under these conditions, in less than 4 hours the fouled fiberglass was disintegrated and only the inner mat was left. Note that it takes about 10-12 hours for the clean rope fiberglass to be digested. The fouled fiberglass was much weaker. This may be attributed to the fact that the fouled fiberglass was in storage for the last two years and the foulants may have weekend the fiberglass structure. The inner mat fibers are about 2535 microns in diameter and take much longer to be digested. In this test it took about a total of 42 hours for the mat to be digested to a point where a $15^{\circ}$ spray nozzle (at $0.8 \mathrm{gpm}$ ) could wash it out of the filter screens in one minute. As shown in Figure 2, the total 42 hour test period included two overnight soaking periods - 10 hours each. Thus, if continuous operating conditions are maintained, the filter would be dissolved in less than 42 hours.

\subsubsection{Test \# 11}

Test \# 11 was similar to Test \# 10 in filter composition (mat inner layer, fouled rope fiberglass outer layer) except that mockup \# 2 was used. In about 5 hours the fouled fiberglass was washed out using \#5.5 (0.060" orifice diameter, $15^{\circ}$ flat spray angle, manufactured by Teel $)$ spray nozzle for 90 seconds. The inner mat layer remained intact after 5 hours. It took a total of 26 hours to breakdown the inner mat layer. Note that mockup \# 2 has 2.3 " $\mathrm{ID}$ as opposed to 0.8 " for mockup \# 3 . Thus the mat fiber had more solution inside in mockup \#2 to attack the fibers.

\subsubsection{Test \# 12}

Test \# 12 was the repeat of Test \# 8. The objective of this test was to determine the digestion characteristics of the mat fiber and its erosion by spraying process water using $15^{\circ}$ nozzles. Mockup \# 1 was packed with $0.924 \mathrm{lbm}$ of mat fiber (25 - 35 micron fiber diameter). The mockup was placed in a fresh batch $\# 4$ of $5 \%$ wt. caustic solution, heated to $100^{\circ} \mathrm{C}$. The air sparge rate was set at $0.8 \mathrm{cfm}$. The filter was raised out of solution every four hour for process water sprays through four nozzles for one minute. At 85 psig supply pressures the four nozzles provide $2.99 \mathrm{gpm}$ of flow. After about 30 hours of operation the outer $1 / 4$ th layer of the filter was digested to the point where it was eroded away with 1 minute spray. After a total of 41 hours the filter was fully digested and eroded. 


\subsubsection{Test \# 13}

Test \# 13 was conducted on mockup \# 3. The inner 1/2" layer was the mat type fiberglass and the outer $1.5^{\prime \prime}$ was packed with clean rope fiberglass. This test was a repeat of Test \# 7 which was conducted at higher sparge rate of $2.24 \mathrm{cfm}$. The digested filter during Test \# 7 was mechanically strong enough to withstand $2.24 \mathrm{cfm}$ sparging and $4.48 \mathrm{cfm}$ was found to be capable of breaking up the filter. Test \#13 was intended to find how the same filter would be dissolved with $0.8 \mathrm{cfm}$ sparging and one minute sprays every four hours. Under these conditions the rope fiber was digested and eroded away in 16 hours. After another 18 hours of operation the inner mat fiber was also fully digested and washed away with 3 minutes of spraying. The total test time was 34 hours.

\subsubsection{Test \# 14}

Test \# 14 was conducted with mockup \# 2 using $1.135 \mathrm{lbm}$ of total fiberglass (23\% more than the nominal mass of $0.924 \mathrm{lbm}$ ). The filter was a composite filter, $0.099 \mathrm{lbm}$ of mat fiber and $1.036 \mathrm{lbm}$ of rope fiber. The objective of this test was to determine the effect of higher packing density on the dissolution and erosion characteristics. The test was conducted at $0.8 \mathrm{cfm}$ and sprayed every four hours for one minute $(3 \mathrm{gpm})$. After about 22 hours, the rope fiber was gone and the inner mat layer remained intact. After a total test time of 47 hours, the mat fiber was also fully digested and eroded away by sparging and spraying.

\subsubsection{Test \# 15}

Test \# 15 was the repeat of Test \#13, using mockup \#3, but at a lower spraying frequency of once every 24 hours instead of every four hours used for Test \#13. The objective of this test was to come up with an operationally simple process where the filter will be placed in boiling caustic solution for about 24 hours under a sparge rate of $0.8 \mathrm{cfm}$ (equivalent of $20 \mathrm{cfm}$ for plant) and then spray it with process water. This would certainly break up the digested rope material. The filter would then be placed in the boiling solution for another 24 hours to chemically break down the mat fiber. At the end of the second 24 hour period the spray would mechanically break down the digested fiberglass. Test \#15 was successful in demonstrating the above scenario. The filter was placed in boiling solution for 12 hours during the day shift. It was left soaked in warm solution overnight. At 24 hours the filter was raised above the solution and inspected. The rope fiber was completely digested but remained intact mechanically in the filter screen. Four minutes of spraying with four nozzles (a total of 12 gallons of water) washed the digested rope fiber. The inner layer of mat fiber remained fibrous and intact. After 12 hours of further soaking in boiling caustic solution with $0.8 \mathrm{cfm}$ sparge rate, the mat fiber was completely washed out from the filter screen and did not require a second spraying operation. It took a total of about 36 hours to complete the test.

\subsubsection{Test \# 16}

Test \# 16 was similar to test \# 15, but mockup \# 2 was used. Following the above process of 24 hours of heating and sparging at $0.8 \mathrm{cfm}$ and then spraying with water, the digested rope was washed out at 26 hours. The remaining mat fiber was washed out after only one hour of heating and sparging. Like Test \#15, no spraying was needed for the inner layer of mat fiber. The total test time was 27 hours.

\subsubsection{7 $\quad$ Test \# 17}

Prior to Test \#17, five mockup filters were dissolved in this solution batch \#4. The objective of Tests \#17 \& 18 was to demonstrate that at least seven filters can be dissolved in a given caustic batch. This information is important since each mist eliminator tank contains three filter 
candles. Once removed from service, multiple of three filter candles will be dissolved. These tests show conclusively that at least six filters can be dissolved easily in a given caustic solution batch, thus minimizing the waste generated. Test \# 17 was performed using mockup \# 3 with 45 grams of mat fiber and 374 grams of bulk rope fiber. After a total of 20 hours of heating and sparging at $0.8 \mathrm{cfm}$, the entire filter was dissolved and mechanically broken down. No spraying was needed.

\subsubsection{Test \# 18}

Test \# 18 was performed using mockup \# 2 with $0.245 \mathrm{lbm}$ of mat fiber and $0.679 \mathrm{lbm}$ of rope fiber. After 24 hours of heating and sparging at $0.8 \mathrm{cfm}$, the digested filter was sprayed with water for two minutes. All the rope and $50 \%$ of the mat fiber was eroded away. After heating and sparging for another 6 hours, the remaining mat was broken down without any spraying. The test completed in 30 hours.

\subsubsection{Solution Sample Analyses}

Throughout the test program, solution samples were drawn from the dissolution tank during and at the conclusion of each test. These samples were drawn to determine (i) the compounds present in the solution, and (ii) to quantify the amount of insoluble solids. The later is important in identifying any potential issues involved with pumping the DWTT solution after the HEME/HEPA dissolutions. Since the fiberglass composition is known (see Tables 1 \& 2) and the chemical reactions of these compounds with $\mathrm{NaOH}$ solution are well understood, a detailed chemical analysis of the samples was not performed. Instead, based on the known glass composition, the amounts of the dissolution products were calculated (Nash, 1993). Results of this calculation are given in Table 5 below. Additionally this stoichiometric calculation yields $154.17 \mathrm{lbm}$ and $159.30 \mathrm{lbm}$ of $\mathrm{NaOH}$ needed for every $100 \mathrm{lbm}$ of clean and fouled fiberglass, respectively. Note that each DWTT batch of $5 \mathrm{wt} \%$ caustic solution contains about $2800 \mathrm{lbm}$ of $\mathrm{NaOH}$ which is, on stoichiometric basis, capable of dissolving about 1750 lbm of fiberglass (about 15 HEME candles). As shown in Table 5, most of the products are

Table 5. Calculated Amounts of Clean and Fouled HEME Dissolution Products (for $100 \mathrm{lbm}$ of glass dissolved)

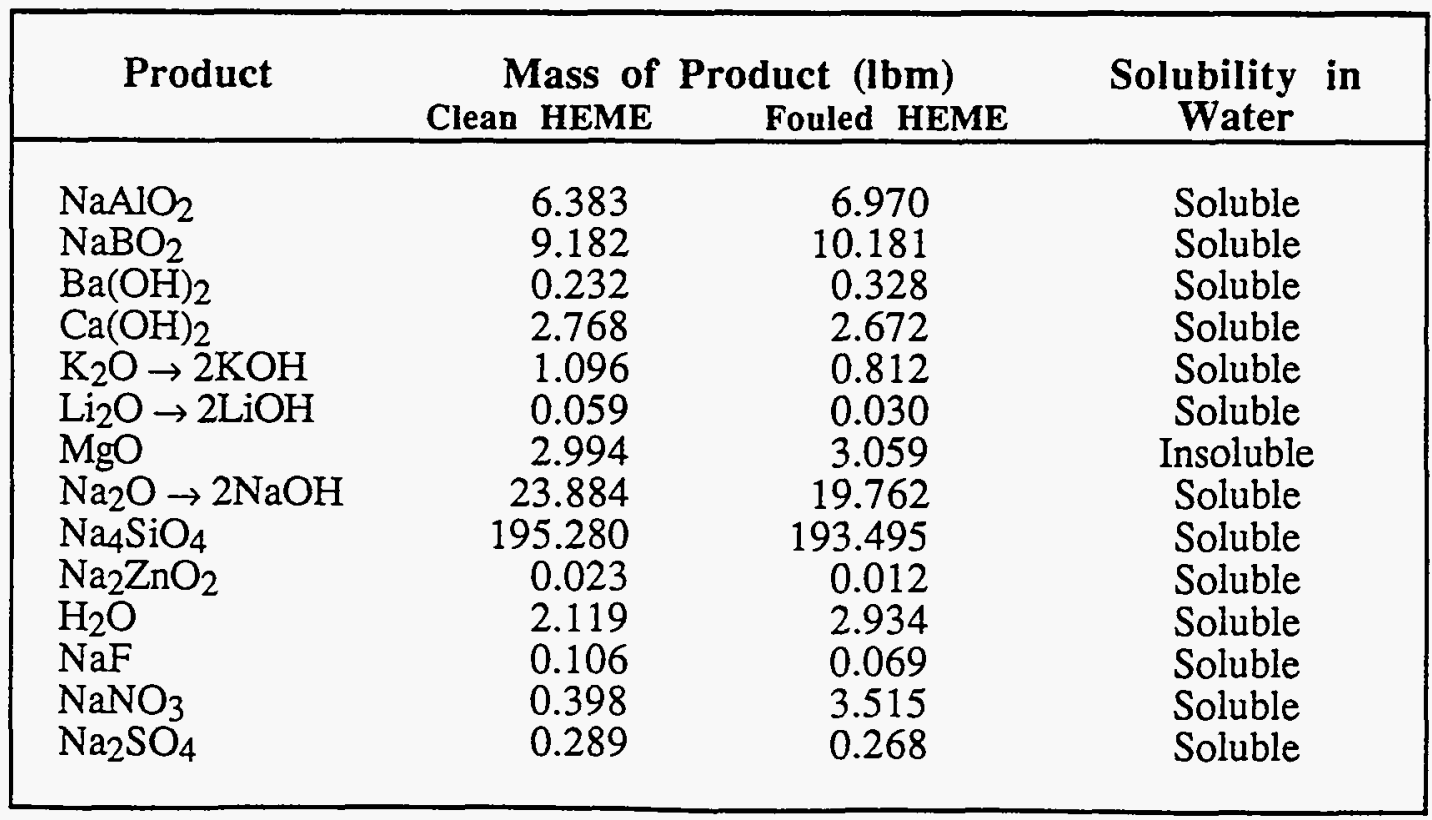


soluble in water, except for $\mathrm{MgO}$ which remains suspended in the solution and settles down over a period of several hours.

As given in Table 5, for every $100 \mathrm{lbm}$ of clean or fouled fiberglass dissolved, about $3 \mathrm{lbm}$ of insoluble sludge $(\mathrm{MgO})$ is produced. Note that each HEME filter candle contains about 115 lbm of fiberglass. Thus each dissolution will yield about $3.45 \mathrm{lbm}$ of insoluble solid contents. For six HEME candles dissolved in the same 6350 gallon solution batch, the total insolubles will be about $20.7 \mathrm{lbm}$. Thus the total insoluble solid content is less than $0.04 \%$ even after 6 dissolutions. For severely fouled filter candles, a similar chemical balance must be performed to determine the amount of insolubles but they are anticipated to be less than $0.1 \%$.

Four solution samples were analyzed by Analytical Services for the total solid contents (soluble and insoluble). Table 6 below gives the description of samples and the analyses results. These samples were drawn from the well mixed pilot-scale facility tank with an initial $5 \mathrm{wt} \% \mathrm{NaOH}$ solution volume of 50.8 gallons. Each HEME mockup dissolution adds $0.924 \mathrm{lbm}$ of fiberglass to the solution.

Table 6. Results of Solution Samples Analyses

\begin{tabular}{|c|c|c|c|c|c|c|}
\hline \multirow[t]{2}{*}{$\begin{array}{c}\text { Solution } \\
\text { Batch } \\
\text { No. }\end{array}$} & \multirow[t]{2}{*}{$\begin{array}{c}\text { No. of } \\
\text { HEMEs } \\
\text { Dissolved }\end{array}$} & \multirow{2}{*}{$\begin{array}{c}\text { Total } \\
\text { Fiberglass } \\
\underset{\text { Mass }}{\text { lbm }}\end{array}$} & \multicolumn{2}{|c|}{$\begin{array}{l}\text { Total } \\
\text { Solids } \\
\text { wt \% }\end{array}$} & \multicolumn{2}{|c|}{$\begin{array}{c}\text { Insoluble Solids } \\
\text { wt } \%\end{array}$} \\
\hline & & & Calculated & Measured & Calculated & Measured \\
\hline $\begin{array}{l}1 \\
2 \\
3 \\
4\end{array}$ & $\begin{array}{c}4 \\
3 \\
3+1 \text { HEPA } \\
5\end{array}$ & $\begin{array}{l}3.696 \\
2.772 \\
3.009 \\
4.620\end{array}$ & $\begin{array}{l}5.8 \\
5.6 \\
5.6 \\
6.0\end{array}$ & $\begin{array}{l}6.92 \\
6.84 \\
6.28 \\
7.66\end{array}$ & $\begin{array}{l}0.025 \\
0.019 \\
0.020 \\
0.031\end{array}$ & $\begin{array}{l}<0.1 \\
<0.1 \\
<0.1 \\
<0.1\end{array}$ \\
\hline
\end{tabular}

It is seen from Table 6 that the measured amounts of total solids (soluble and insoluble) are consistently higher than the calculated ones. This is attributed to the uncertainty in weight measurements. Most of the solid mass is, however, soluble and the insolubles could not be measured accurately due to the uncertainties in the weight measurements and the size of the sample that could be processed by the Analytical Lab. However, the total amount of insolubles is so small that it does not pose any pumping problem.

\subsection{CONCLUSIONS}

The Pilot-Scale HEME/HEPA dissolution test program was successful in developing a definitive process of dissolving and disintegrating HEME/HEPA filters using 5 wt\% NaOH solution. Based upon the 18 dissolution tests performed, the following conclusions are drawn.

1. The HEME/HEPA filter medium (fiberglass) can be dissolved in a single step process using $5 \mathrm{wt} \% \mathrm{NaOH}$ solution instead of a 3 step process (caustic-acid-caustic) proposed by earlier studies.

2. The dissolution process of HEMEs has two stages - chemical digestion of the filter and mechanical erosion of the digested filter. The digestion time primarily depends upon the 
fiber size and to some extent on the packing density. The rope fiber ( $7-12$ micron diameter fibers) takes about 12 hours to get digested in boiling caustic solution ( $5 \mathrm{wt} \%$ ) with 0.8 cfm sparge rate (corresponding to $20 \mathrm{cfm}$ plant sparge rate) and the mat fiber (25-35 micron diameter fibers) take about 24 to 40 hours for digestion. The digested filter remains mechanically intact as the consistency of packed snow and requires very high levels of air sparging ( $112 \mathrm{cfm}$ - twice the plant maximum sparge rate) or spraying with process water. Increased air sparging was found to be marginally successful. Spraying water is a much more effective process of removing the digested filter from the screens. The available samples of fouled HEME fiberglass required less time for dissolution.

3. The HEPA filters can be dissolved in about 2 hours using a boiling caustic solution without any water spraying. A new HEPA filter was dissolved in the test program. The available fouled HEPA was structurally much weaker than the new one, thus requiring less time for dissolution/disintegration.

4. Presoaking the filter in warm caustic solution $\left(\sim 50^{\circ} \mathrm{C}\right)$ for about 16 hours does not help the dissolution process. Instead, it gelled the digested filter requiring very high solution agitation levels for its erosion.

5. Pumping solution through the filter fiberglass matrix is not practical due to high pressure drop associated with liquid flow. Additionally, as the chemical digestion progresses, the filter becomes impervious.

6. In a given solution batch, many HEME/HEPA filters can be dissolved. On a stoichiometric basis, a 6350 gallons $5 \mathrm{wt} \% \mathrm{NaOH}$ solution batch in DWTT has enough $\mathrm{NaOH}$ sufficient to dissolve about 15 HEME filter candles (each containing about 115 pounds of fiberglass). The test program demonstrated that at least 7 HEME filters can be dissolved. Considering the total mass of HEPA fiberglass, twice as many HEPAs can be dissolved.

7. The products of dissolution are easily pumpable by a centrifugal pump. However, the solution sample lines at the tank bottom were plugged with the insolubles and high pressure air was periodically used to unclog them. A chemical balance shows that the total amount of insoluble solids produced as a result of each 115 pound HEME dissolution in DWTT is estimated to be 3.45 pounds. On stoichiometric basis, about 15 HEME candles can be dissolved in one solution batch. Under these limiting conditions the total insolubles will be about $52 \mathrm{lbm}$ which is less than $0.1 \mathrm{wt} \%$. Thus pumping the solution even after 15 dissolutions does not pose any problem as long as the solution is agitated and well mixed prior to pumping.

8. In order to mechanically break down the digested filter, it is proposed to spray process water using spray nozzles. The pilot scale facility used four stainless steel nozzles (\#5.5, $0.060^{\prime \prime}$ orifice diameter, $15^{\circ}$ flat spray angle) manufactured by Teel, installed $90^{\circ}$ apart around the dissolution tank. The nozzles were 6 " above the solution level and about 12 " away from the filter target. The four nozzles provided $3 \mathrm{gpm}$ flow rate at a supply pressure of 85 psig. The spray field provides a $360^{\circ}$ coverage of the filter cage. For DWTT operation it is proposed to install a new spray ring with 30 nozzles described above. A schematic of the proposed ring is shown in Figure 3. The anticipated flow rate will be about 22 gpm at 85 psig supply pressure. The new spray ring should be installed about 12" above the liquid surface. A 15 minute spray would add about 330 gallons of water, raising about 5 " of solution level in DWTT. The spray water can be used to compensate the make up water needed to replace the water lost during boiling operation. It is proposed that the new spray ring should be characterized prior to its installation. The hydraulic characterization must ensure a uniform flow rate through each nozzle, total flow rate versus supply pressure, and $360^{\circ}$ spray field around the filter screen as shown in Fig. 3. The 


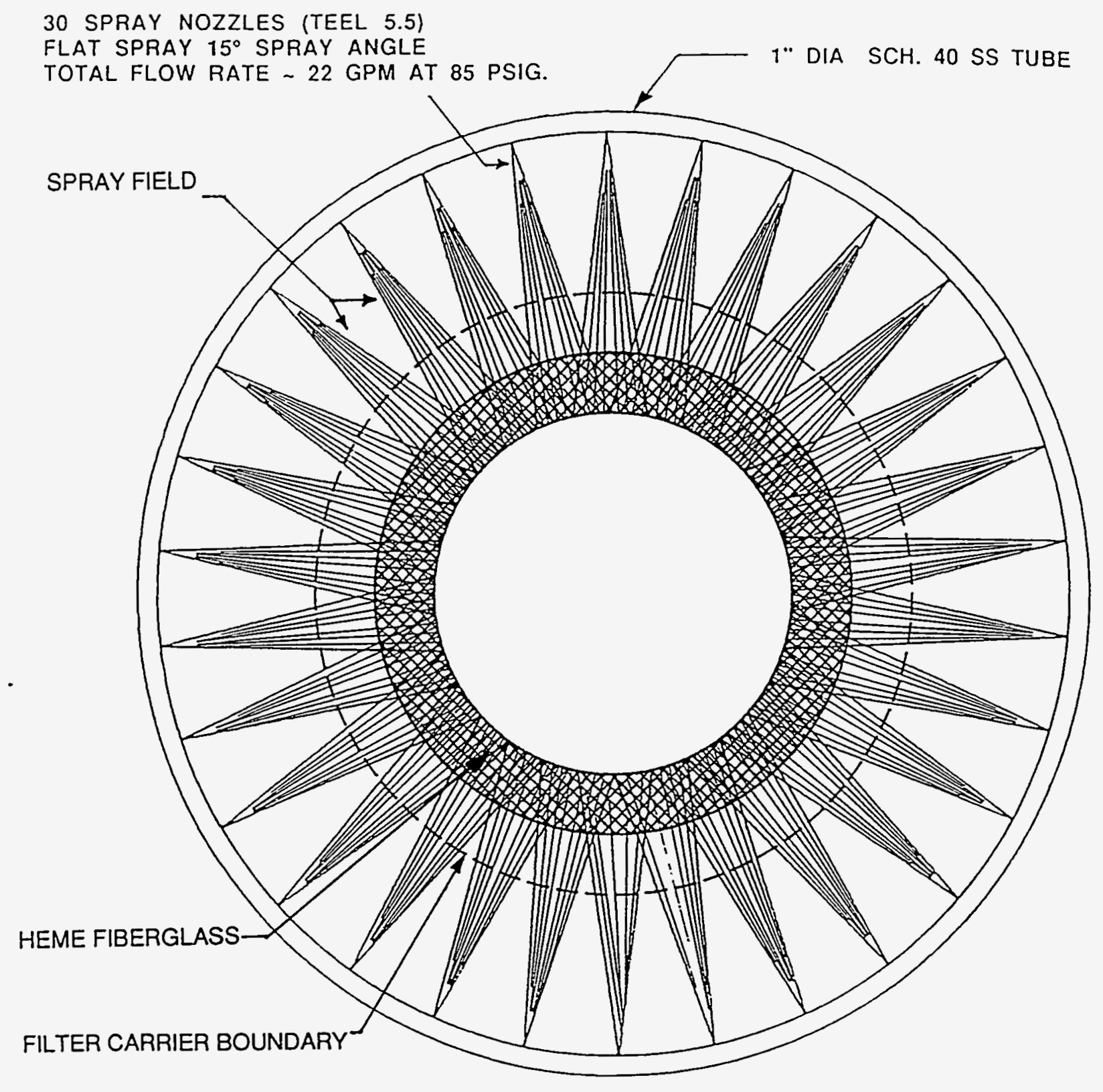

Figure 3. Proposed Concept for the Additional Spray Ring to Wash Out the Digested Filter 
water supply to the additional spray ring can be common to the supply to the existing ring near the top of the DWTT. Thus, when the process water is turned on, both the rings will be spraying water, though, only the new ring will be eroding the digested fiberglass. Note that the nozzles inthe existing spray ring are facing downwards $\left(60^{\circ}\right.$ from the horizontal plane) and cannot spray radially inwards.

9. The recommended dissolution process for DWTT operation is:

1. Immerse HEME filter candle in 6350 gallons of $5 \mathrm{wt} \% \mathrm{NaOH}$ solution.

2. Set air sparge rate to $20 \mathrm{cfm}$ and heat the solution to boiling condition for 24 hours, adding make up water to maintain the level necessary to cover the steam coils. All the rope fiberglass would be digested during this operation.

3. Stop air sparging and slowly traverse the filter candle up and down across the new process water spray ring with the water spray on for 15 minutes. This will ensure removal of the digested rope fiber from the filter screens.

4. Immerse the filter candle in the solution and repeat step 2. All the mat fiber would be digested during this operation.

5. Repeat step 3 to wash out the digested mat fiber.

6. Using the existing spray ring near the top of DWTT and the new spray ring, raise and wash the filter metal cage for its disposal.

7. Dissolve other filter candles as needed in the same solution batch (at least $6 \mathrm{HEME}$ candles can be dissolved).

\subsection{REFERENCES}

J. L. Bransford, Solid Waste Process Development Weekly Highlights, (January 30, 1985 and March 21, 1985)

C. A. Cicero, HEME and HEPA Filter Element Dissolution Process, WSRC-TR-92-549, Savannah River Site, Aiken, SC 29808 (1992).

D. E. Clark, C. G. Pantano, Jr., and L. L. Hench, Corrosion of Glass, Published by Books for Industry and The Glass Industry, Div. of Magazines for Industry, Inc. New York, 1979.

B. A. Daugherty, Dissolution of HEPA and HEME Filtration Media, DPST-84-376, Savannah River Site, Aiken, SC 29808 (1984).

C. M. Jantzen, Summary and Status of HEME/HEPA Filter Dissolution for DWPF (Technology Issue 10.1), WSRC-89-533, Savannah River Site, Aiken, SC 29808 (1989).

C. A. Nash, Sodium Hydroxide Needed to HEME/HEPA Glass Dissolution, Memo to Z. H. Qureshi, SRT-ETF-930252, Savannah River Technology Center, Aiken, SC 29808 (November 2, 1993). 
APPENDIX A

CHRONOLOGICAL DESCRIPTIONS OF HEME/HEPA DISSOLUTION TESTS 


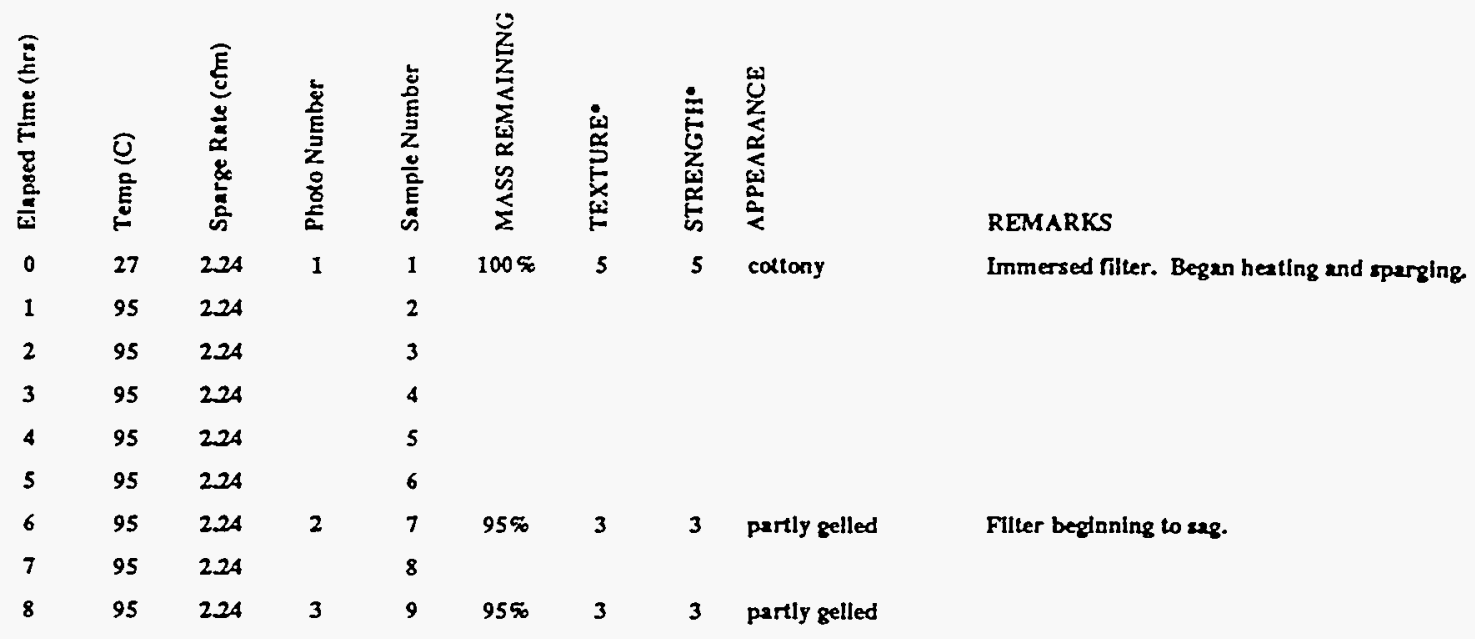

16 HOUR SOAKING PERIOD, NO HEATING, NO SPARGING

$\begin{array}{llllllllll}24 & 45 & 224 & & & & & & & \\ 25 & 95 & 224 & & & & & & & \\ 26 & 95 & 224 & 4 & 10 & 80 \% & 1 & 1 & \text { packed snow } & \text { Hall inch thinner all around. } \\ 27 & 95 & 224 & & & & & & & \text { An inch thinner all around. } \\ 28 & 95 & 224 & 5 & 11 & 50 \% & 1 & 1 & \text { packed snow } \\ 29 & 95 & 224 & & & & & & & \text { Filter frame is completely empty. } \\ 30 & 95 & 224 & 6 & 12 & 0 \% & & & & \end{array}$

3 Moderate rubbing will disintegrate most of the fibers into perte.

2 Slight rubbing will disintegrate all the fibers into paste.

1 No mechanical strength, any slight disturbance breaks down the material.

$\begin{array}{ll}5 & \text { Completely fibrous } \\ 4 & \text { Mostly fibrous, slightly digested } \\ 3 & \text { Partly fibrous, partly digested } \\ 2 & \text { Slightly fibrous, mostly digested } \\ 1 & \text { Completely digested }\end{array}$




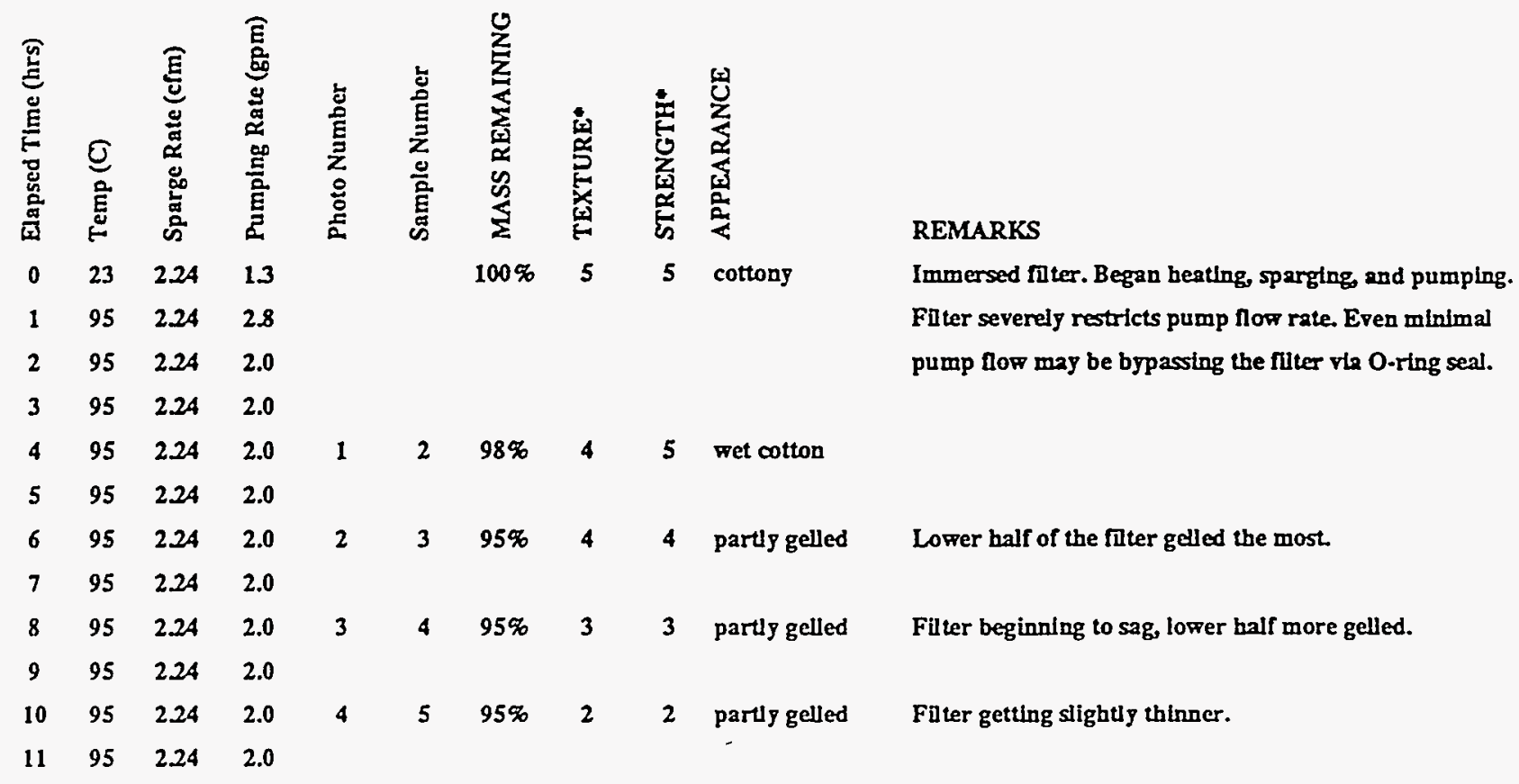

16 HOUR SOAKING PERIOD, NO HEATING, NO SPARGING

$\begin{array}{cccccccccl}27 & 39 & 2.24 & 2.0 & 5 & 6 & 95 \% & 2 & 2 & \text { partly gelled } \\ 28 & 95 & 2.24 & 2.0 & 6 & 7 & 90 \% & 1 & 1 & \text { packed snow } \\ 28.6 & 95 & 2.24 & 2.0 * * & 7 & & 60 \% & 1 & 1 & \text { packed snow } \\ 29 & 95 & 2.24 & 2.0 & 8 & & 50 \% & 1 & 1 & \text { packed snow } \\ 30 & 95 & 2.24 & 2.0 & 9 & & 25 \% & 1 & 1 & \text { packed snow } \\ 30.3 & 95 & 2.24 & 2.0 & & 8 & 0 \% & & & \end{array}$

33.0
9
Started heating, sparging and pumping. Uniform consistency, top to bottom.

**1 min. at $9.10 \mathrm{gpm}$ without filer leakby.

High pump rates quickly break apart remaining mass. Onjy a small portion remains.

Fiter frame is completely empty.

Sample taken of sudge settled on tank bottom.

*KEY

5 Full strength, rubbing between fingers will not disintegrate fibers into parte.

4 Vigorous rubbing will disintegrate some of the fibers into paste.

3 Moderate rubbing will disintegrate most of the fibers into paste.

2 Slight rubbing will disintegrate all the fibers into paste.

1 No mechanical strength, ang slight disturbance breaks down the material.

$\begin{array}{ll}5 & \text { Completely fibrous } \\ 4 & \text { Mostly fibrous, slightly digested } \\ 3 & \text { Partly fibrous, partly digested } \\ 2 & \text { Slightly fibrous, mostly digested } \\ 1 & \text { Completely digested }\end{array}$




\section{CHRONOLOGICAL DESCRIPTIC - FOR HEME DISSOLUTION TEST}

Tesk SRT-ETF-TT-93-048

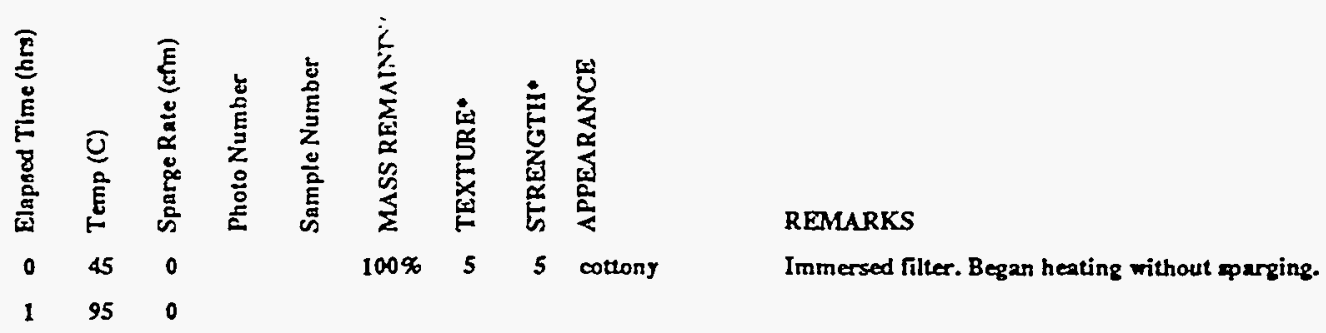

17 HOUR SOAKING PERIOD, NO HEATING, NO SPARGING

$\begin{array}{llllll}18 & 41 & 0 & 1 & \\ 19 & 95 & 0.2 & & \text { Began lightly sparging for uniform heating. } \\ 20 & 95 & 0.2 & 2 & \text { Siudge clogged sightglass. } \\ 21 & 95 & 224 & & \text { Top half gelled the most Bottom more fibrous } \\ 22 & 95 & 224 & 3 & \\ 23 & 95 & 224 & & \text { Twice ran pump } 1 \text { minute at } 1 \text { gpm. No offect. } \\ 24 & 95 & 224 & 4 & \text { Very thin fibrous structure remaining. } \\ 25 & 95 & 224 & & \end{array}$

16 HOUR SOAKING PERIOD, NO HEATING, NO SPARGLNG

\begin{tabular}{|c|c|c|c|c|c|c|c|c|c|}
\hline 41 & 95 & 0.96 & & 5 & & & & & Began heating and light sparging. Filter meems ready to break apart \\
\hline 42 & 95 & 0.96 & & 6 & & & & & Filter seems to erode more slowly at lower sparge ratea \\
\hline 43 & 95 & 0.96 & & & & & & & \\
\hline 44 & 95 & 0.96 & & & & & & & \\
\hline 45 & 95 & 0.96 & & 7 & & & & & \\
\hline 46 & 95 & 0.96 & & & & & & & \\
\hline 46.5 & 95 & 3.36 & & 8 & & & & & Increased sparge rate did not accelerate erosion. \\
\hline 47 & 95 & 3.36 & & & & & & & \\
\hline 47.5 & 95 & 224 & 1 & 9 & So\% & 1 & 1 & packed snow & 10 minutes of pumping at $10 \mathrm{gpm}$ did accelerate crosion. \\
\hline 48 & 95 & 224 & 2 & & $0 \%$ & & & & 5 more minutes of pumping at $10 \mathrm{gpm}$ left the fiker frame empty. \\
\hline \multirow[t]{11}{*}{89} & & & & 10 & & & & & Sample taken of sludge settled on tank bottom. \\
\hline & & & & & •KEY & & 5 & \multicolumn{2}{|c|}{ Full strength, rubbing between lingers will not disintegrate fibers into paste. } \\
\hline & & & & & & & 4 & \multicolumn{2}{|c|}{ Vigorous rubbing will disintegrate some of the fibers into paste. } \\
\hline & & & & & & & 3 & \multicolumn{2}{|c|}{ Moderate rubbing will disintegrate most of the nibers into paste. } \\
\hline & & & & & & & 2 & \multicolumn{2}{|c|}{ Stight rubbing will disintegrate all the fibers into paste } \\
\hline & & & & & & & 1 & \multicolumn{2}{|c|}{ No mechanical strength, any slight disturbance breaks down the material. } \\
\hline & & & & & & 5 & & \multicolumn{2}{|c|}{ Completely fibrous } \\
\hline & & & & & & 4 & & \multicolumn{2}{|c|}{ Mosuly fibrous, slightly digested } \\
\hline & & & & & & 3 & & \multicolumn{2}{|c|}{ Partly fibrous, partly digested } \\
\hline & & & & & & 2 & & \multicolumn{2}{|c|}{ Slightly fibrous, mastly digested } \\
\hline & & & & & & 1 & & \multicolumn{2}{|c|}{ Completely digested } \\
\hline
\end{tabular}




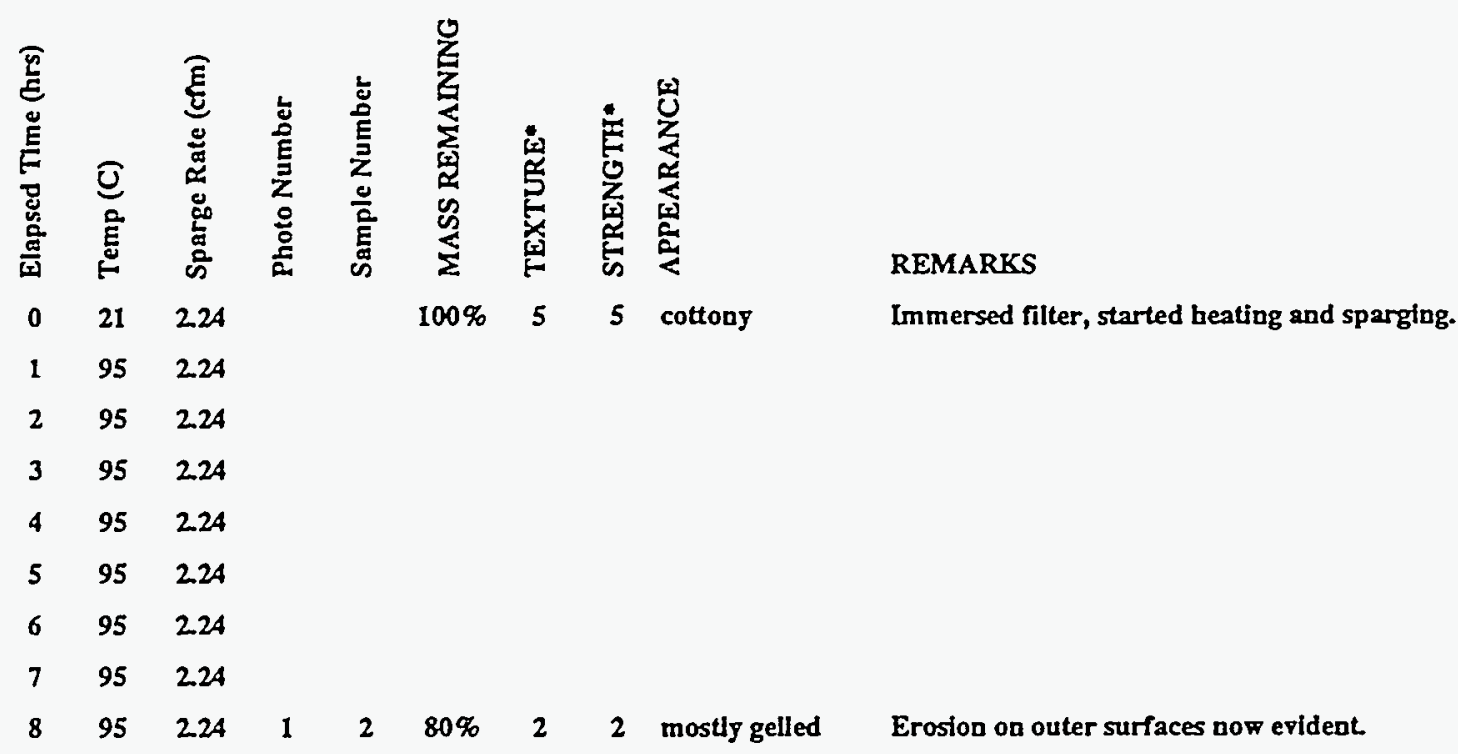

16 HOUR SOAKING PERIOD, NO HEATING, NO SPARGING

$\begin{array}{lllllllll}24 & 49 & 2.24 & & & & & & \\ 25 & 95 & 2.24 & 2 & 3 & 75 \% & 1 & 2 & \text { packed snow } \\ 26 & 95 & 2.24 & 3 & 4 & 70 \% & 1 & 1 & \text { packed snow } \\ 27 & 95 & 2.24 & 4 & 5 & 65 \% & 1 & 1 & \text { packed snow } \\ 28 & 95 & 224 & 5 & 6 & 60 \% & 1 & 1 & \text { packed snow } \\ 29 & 95 & 2.24 & 6 & & 60 \% & 1 & 1 & \text { packed snow } \\ 30 & 95 & 4.48 * * & 7 & & 25 \% & 1 & 1 & \text { packed snow }\end{array}$

$\begin{array}{lll}31 & 95 & 4.48\end{array}$
$0 \%$

-KEY
Solution is clear. Sludge settled on tank bottom.

A few capities visible on the surface.

More erosion evident on the upper portion.

Erosion rate seems falrly steady.

Erosion rate may be slowing.

No changes noted.

High sparge rate greatly increased erosion rate

- Sprayed a stream of cold water ( $0.6 \mathrm{gpm})$ for about 1 minute direclly at tbe remaining mass, which acted very much like spraying at tightly-packed melting snow.

The filter frame is completely empty.

4 Vigorous rubbing will disintegrate some of the fibers into paste.

3 Moderate rubbing will disintegrate most of the fibers into paste.

2 Slight rubbing will disintegrate all the fibers into paste.

1 No mechanical strength, any slight disturbance breaks down the material.

$5 \quad$ Completely fibrous

4 Mostly fibrous, slightly digested

3 Partly fibrous, partly digested

2 Slightly fibrous, mostly digested

1 Completely digested 


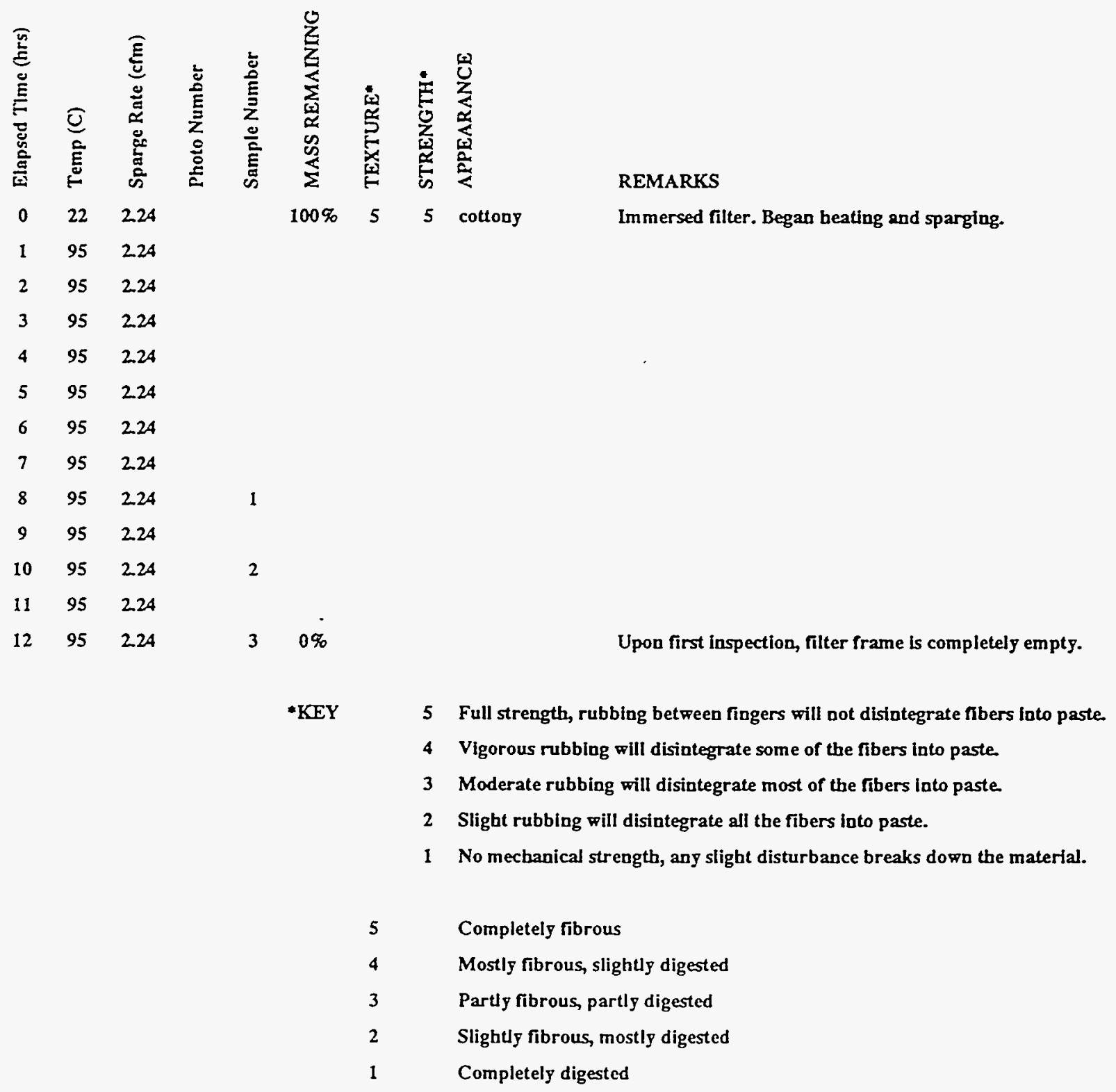




\begin{tabular}{|c|c|c|c|c|c|c|c|c|c|}
\hline 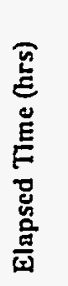 & 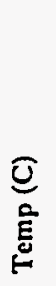 & 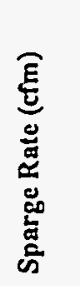 & 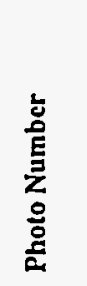 & 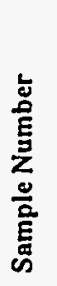 & 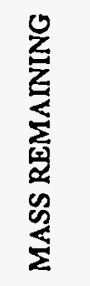 & 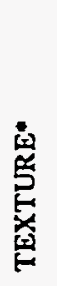 & 点 & 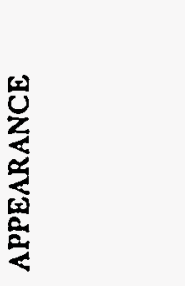 & REMARKS \\
\hline 0 & 28 & 0.8 & & & $100 \%$ & 5 & 5 & cottony & Immersed filter. Began beating and sparging. \\
\hline 1 & 95 & 0.8 & & & & & & & \\
\hline 8 & 95 & 0.8 & 1 & 1 & $98 \%$ & 3 & 3 & wet cotton & Slight erosion evident. \\
\hline 10 & 95 & 0.8 & 2 & 2 & $95 \%$ & 3 & 3 & wet cotton & Erostion continuing. \\
\hline 12 & 95 & 0.8 & 3 & 3 & $90 \%$ & 2 & 2 & partly gelled & \\
\hline 13 & 95 & 0.8 & 4 & 4 & $90 \%$ & 2 & 2 & partly gelled & \\
\hline 14 & 95 & 0.8 & 5 & & $85 \%$ & 2 & 2 & partly gelled & \\
\hline 15 & 95 & 0.8 & 6 & & $85 \%$ & 2 & 2 & partly gelled & \\
\hline 16 & 95 & 0.8 & 7 & & $85 \%$ & 2 & 2 & partly gelled & \\
\hline 17 & 95 & 0.8 & 8 & & $85 \%$ & 2 & 2 & partiy gelled & Filter starting to look pitted. \\
\hline 18 & 95 & 0.8 & 9 & & $85 \%$ & 2 & 2 & partly gelled & \\
\hline 19 & 95 & 0.8 & 10 & & $85 \%$ & 2 & 2 & partly gelled & \\
\hline 20 & 95 & 0.8 & & & & & & & Filter starting to sag. \\
\hline 22 & 95 & 0.8 & 11 & & $80 \%$ & 1 & 1 & packed saow & No further erosion noted. \\
\hline 23 & 95 & 0.8 & 12 & & $80 \%$ & 1 & 1 & packed snow & No further erosion noted. \\
\hline 24 & 95 & 0.8 & 13 & & $80 \%$ & 1 & 1 & packed soow & No further erosion noted. \\
\hline 40 & 95 & 2.24 & 14 & & $80 \%$ & 1 & 1 & packed snow & Raised sparge rate to accelerate erosion rate. \\
\hline 41 & 95 & 224 & 15,16 & & $70 \%$ & 1 & 1 & packed snow & More erosion and sagging evident. \\
\hline 42 & 95 & 224 & 17 & & $60 \%$ & 1 & 1 & packed snow & More erosion, sagging to one side. \\
\hline 42.5 & 95 & 2.24 & 18 & & $50 \%$ & 1 & 1 & packed snow & Most mass shifted to one side of filter frame. \\
\hline 43 & 95 & 2.24 & & 5 & $0 \%$ & & & & Filter frame is completely empty. \\
\hline
\end{tabular}

*KEY

5 Full strength, rubbing between fingers will not disintegrate fibers into paste.

4 Vigorous rubbing will disintegrate some of the fibers lnto paste.

3 Moderate rubbing will disintegrate most of the fibers into paste.

2 Slight rubbing will disintegrate all the fibers into paste.

1 No mechanical strength, any slight disturbance breaks down the material.

$\begin{array}{ll}5 & \text { Completely fibrous } \\ 4 & \text { Mostly fibrous, slightly digested } \\ 3 & \text { Partly fibrous, partly digested } \\ 2 & \text { Slightly fibrous, mostly digested } \\ 1 & \text { Completely digested }\end{array}$




\begin{tabular}{|c|c|c|c|c|c|c|c|c|c|}
\hline 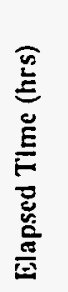 & 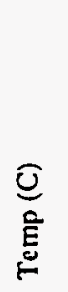 & 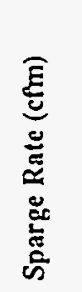 & 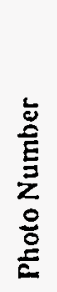 & 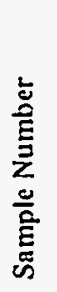 & 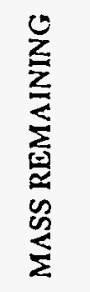 & 兽 & 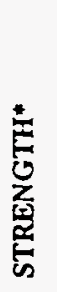 & 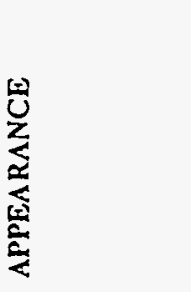 & REMARKS \\
\hline 0 & 22 & 2.24 & & & $100 \%$ & 5 & 5 & cottony & Immersed filter. Began heating and sparging. \\
\hline 4 & 95 & 2.24 & & 1 & & & & & \\
\hline 6 & 95 & 2.24 & & 2 & & & & & \\
\hline 8 & 95 & 2.24 & 1 & 3 & $85 \%$ & 2 & 3 & partly gelled & \\
\hline 10 & 95 & 2.24 & 2 & 4 & $85 \%$ & 2 & 2 & packed soow & Filter beginning to sag. \\
\hline 12 & 95 & 2.24 & 3 & & $80 \%$ & 1 & 1 & packed snow & Erosion rate slowing. \\
\hline 18 & 95 & 2.24 & 4 & & $80 \%$ & 1 & 1 & packed soow & \\
\hline 22 & 95 & 2.24 & 5 & & $80 \%$ & 1 & 1 & packed soow & No erosion noted. Filter sagging more. \\
\hline 30 & 95 & 2.24 & 6 & 5 & $75 \%$ & 1 & 1 & packed snow & Very little erosion noted. \\
\hline 36 & 95 & 3.36 & & & & & & & Raised sparge rate to accelerate erosion rate. \\
\hline 37 & 95 & 3.36 & & & & & & & No further erosion noted. \\
\hline 37.5 & 95 & 4.48 & & & & & & & Raised sparge rate to accelerate erosion rate. \\
\hline 38.5 & 95 & 4.48 & 7 & & $40 \%$ & 2 & 2 & cotton candy & Digested outer rope washed away, leaving inner mat portlon. \\
\hline 3 & 95 & 4.48 & & & $25 \%$ & 2 & 2 & cotton candy & Inver mat still exhibits some fibrous structure and strength. \\
\hline 39.5 & 95 & 4.48 & 8 & 6 & $10 \%$ & 2 & 2 & cotton candy & Stopped testing over the weekend. \\
\hline
\end{tabular}

66 HOUR SOAKING PERIOD, NO FEATING, NO SPARGING

$\begin{array}{llllllll}106 & 23 & 4.48 & 10 \% & 1 & 1 & \text { packed snow } & \begin{array}{l}\text { Resumed sparging without heating. } \\ 107\end{array} \\ 23 & 4.48 & 0 \% & & & & \text { Filter frame is completely empty. }\end{array}$

* KEY 5 Full strength, rubbing between fingers will not disintegrate fibers Into paste.

4 Vigorous rubbing will disintegrate some of the fibers into paste.

3 Moderate rubbing Fill disintegrate most of the fibers into paste.

2 Slight rubbing will disintegrate all the fibers into paste.

1 No mechanical strength, any slight disturbance breaks down the material.

$\begin{array}{ll}5 & \text { Completely fibrous } \\ 4 & \text { Mostly fibrous, slightly digested } \\ 3 & \text { Partly fibrous, partly digested } \\ 2 & \text { Slightly fibrous, mostly digested } \\ 1 & \text { Completely digested }\end{array}$




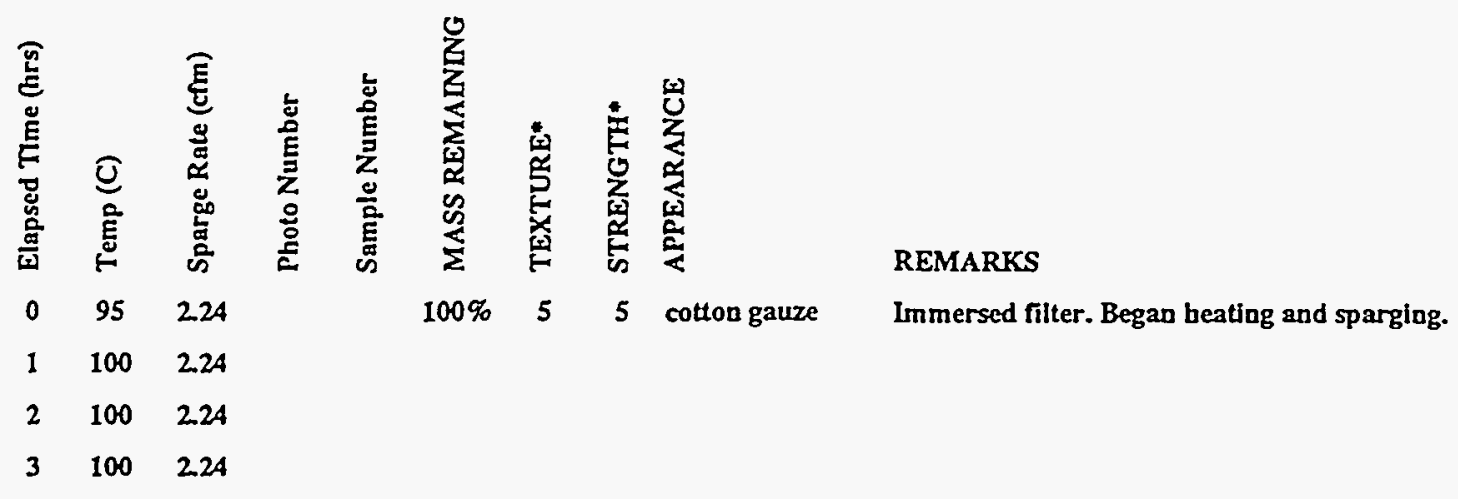

12 HOUR SOAKING PERIOD, NO HEATING, NO SPARGING

$\begin{array}{llllcl}15 & 48 & 2.24 & 1 & & \text { The pink webbing on the mat bas faded to white. } \\ 16 & 100 & 2.24 & & & \\ 17 & 100 & 2.24 & & & \\ 18 & 100 & 2.24 & 1 & 100 \% & 4 \text { cotton gauze } \\ 19 & 100 & 2.24 & & & \\ 20 & 100 & 2.24 & & \\ 21 & 100 & 2.24 & 2 & \\ 22 & 100 & 2.24 & & \\ 23 & 100 & 2.24 & \end{array}$

15 HOUR SOAKING PERIOD, NO HEATING, NO SPARGING

$\begin{array}{ccc}38 & 44 & 2.24 \\ 39 & 100 & 224 \\ 40 & 100 & 2.24 \\ 41 & 100 & 2.24 \\ 42 & 100 & 2.24 \\ 43 & 100 & 2.24 \\ 44 & 100 & 2.24 \\ 45 & 100 & 2.24 \\ 46 & 100 & 224 \\ 47 & 100 & 2.24\end{array}$

\begin{abstract}
For scoping purposes, 2 nozzles were prepared to determine their effectiveness in croding the material.

Nozzle \#1 (11/64 " l.d.) delivers $1.6 \mathrm{gpm}$ at 85 psi.

Nozzle 2 (1/16 " i.d.) delivers $0.6 \mathrm{gpm}$ at 85 psi.

Nozzle \#1 merely 'pushes' the fiber, but nozzle \#2 makes a $1 / 4$ " wide clean vertical slice ( $0.6^{\prime \prime}$ thick) along the entire filter length in about $31 / 2$ minutes from a distance of $13^{\prime \prime}$.
\end{abstract}

18 HOUR SOAKING PERIOD, NO HEATING, NO SPARGING

$\begin{array}{cccccccc}65 & 42 & 2.24 & & 60 \% & 1 & 1 & \text { packed snow } \\ 66 & 100 & 2.24 & 4 & 0 \% & & & \end{array}$

The vertical slice has doubled in width to about $1 / 2 "$. The mass collapsed suddenly and the filter frame is empty. Several cottonball-size pieces are visible in the solution. 


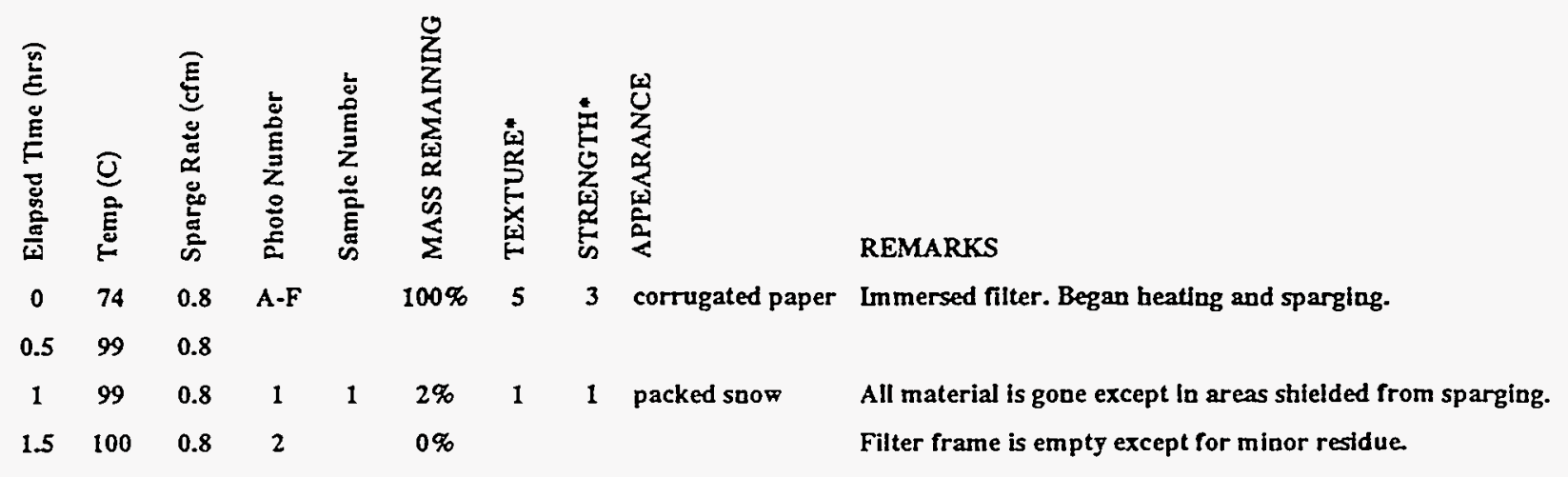

- KEY 5 Full strength, rubbing between fingers will not disintegrate fibers into paste.

4 Vigorous rubbing will disintegrate some of the fibers into paste.

3 Moderate rubbing will disintegrate most of the fibers into paste.

2 Sligbt rubbing will disintegrate all the fibers into paste.

1 No mechanical strength, any slight disturbance breaks down the material.

$\begin{array}{ll}5 & \text { Completely fibrous } \\ 4 & \text { Mostly fibrous, slightly digested } \\ 3 & \text { Partly fibrous, partly digested } \\ 2 & \text { Slightly fibrous, mostly digested } \\ 1 & \text { Completely digested }\end{array}$




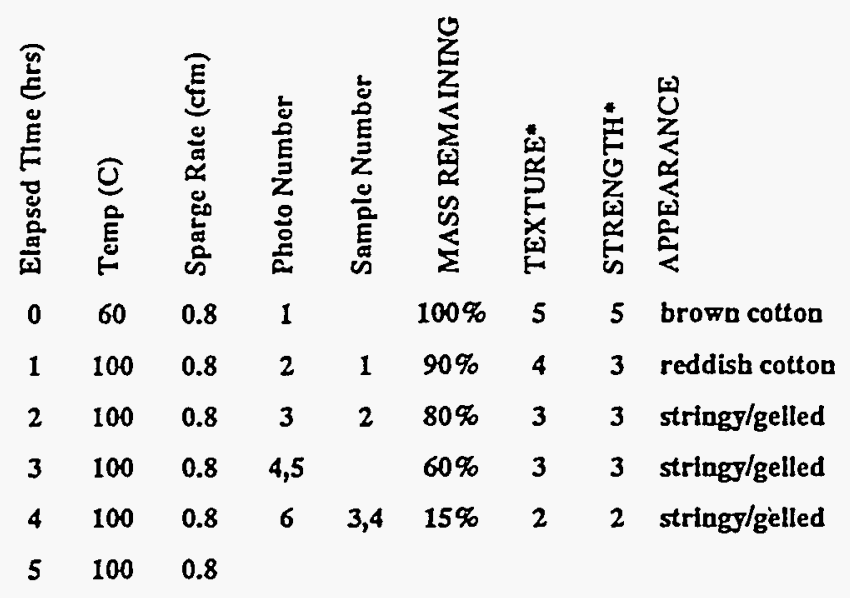$$
\begin{array}{lll}
10 & 100 & 0.8
\end{array}
$$$$
21 \quad 100 \quad 0.8
$$$$
\begin{array}{lll}
22 & 100 & 0.8
\end{array}
$$$$
\begin{array}{lll}
23 & 100 & 0.8
\end{array}
$$$$
\begin{array}{lll}
24 & 100 & 0.8
\end{array}
$$$$
\begin{array}{lll}
29 & 100 & 0.8
\end{array}
$$$$
\begin{array}{llll}
30 & 100 & 0.8 & 7
\end{array}
$$$$
\begin{array}{lll}
31 & 100 & 0.8
\end{array}
$$$$
\begin{array}{lll}
32 & 100 & 0.8
\end{array}
$$

\section{HOUR SOAKING PERIOD, NO HEATING, NO SPARGING}

\section{REMARKS}

\section{HOUR SOAKING PERIOD, NO HEATING, NO SPARGING}

Immersed filter. Began heating and sparging.

Some loose fibers hanging from frame. Filter discoloring.

Discoloration continues. The shorter strands of fouled rope may be washing out before being fully digested.

The Inner mat and a few strands of fouled rope remain. Sprayed mat from $13^{\mathrm{N}}$ away for $1 \mathrm{~min}$. at $0.8 \mathrm{gpm}$. No erosion.

No further erosion noted.

Sagging slightly, bottom moze digested than top.

Sprayed mat from $13^{n}$ away for $2 \mathrm{~min}$. at $0.8 \mathrm{gpm}$. No erosion.

Sprayed mat from 13" for $1 \mathrm{~min}$.(30 sec each side) at $0.8 \mathrm{gpm}$.

Minor erosion occurred.

Sprayed mat from 13" for $1 \mathrm{~min}$. (30 sec each side) at $0.8 \mathrm{gpm}$. This left the filter frame completely empty.

*KEY 5 Full strength, rubbing between fingers will not disintegrate fibers into paste.

4 Vlgorous rubbing will disintegrate some of the fibers into paste.

3 Moderate rubbing will disintegrate most of the fibers into paste.

2 Slight rubbing fill disintegrate all the fibers into paste.

1 No mechanical strength, any slight disturbance breaks down the material.

$\begin{array}{ll}5 & \text { Completely fibrous } \\ 4 & \text { Mostly fibrous, slightly digested } \\ 3 & \text { Partly fibrous, partly digested } \\ 2 & \text { Slightly fibrous, mostly digested } \\ 1 & \text { Completely digested }\end{array}$




\begin{tabular}{|c|c|c|c|c|c|c|c|c|c|}
\hline 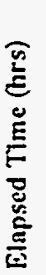 & 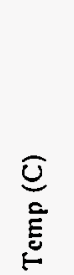 & 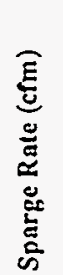 & 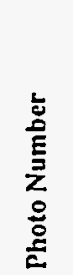 & 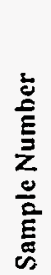 & 忘 & 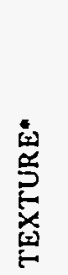 & 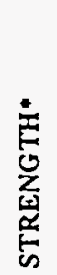 & 国 & REMARKS \\
\hline 0 & 100 & 0.8 & & & $100 \%$ & 5 & 5 & brown cotton & Immersed filter in preheated solution. Began sparging. \\
\hline 1 & 100 & 0.8 & & & & & & & Some loose strands hangiog from frame. Filter discoloring. \\
\hline 2 & 100 & 0.8 & & 1 & & & & & Some smaller strands washed out from midsection. \\
\hline 3 & 100 & 0.8 & & & & & & & \\
\hline 4 & 100 & 0.8 & & & & & & & The inner mat and about $1 / 4$ of the rope remaln. \\
\hline 5 & 100 & 0.8 & 1,2 & & $30 \%$ & 2 & 1 & cotton gauze & $90 \mathrm{sec}$ spray ( $3 \times 30 \mathrm{sec}$ from 120 degree angles) at $0.8 \mathrm{gpm}$ \\
\hline 6 & 100 & 0.8 & & & $30 \%$ & 4 & 4 & cotton gauze & washed away rope, left inner mat intact. \\
\hline 7 & 100 & 0.8 & & & $30 \%$ & 4 & 4 & cotton gauze & No further erosion noted. \\
\hline \multicolumn{10}{|c|}{10 HOUR SOAKING PERIOD, NO HEATING, NO SPARGING } \\
\hline 17 & 56 & 0.8 & 3 & 2 & $30 \%$ & 4 & 4 & cotton gauze & 30 sec spray caused no further erosion. \\
\hline 24 & 100 & 0.8 & 4,5 & 3 & $15 \%$ & 3 & 2 & cotton gauze & $\begin{array}{l}\text { Top half of inner mat disintegrated without spray. Then sprayed } \\
2 \times 30 \mathrm{sec} \text { at } 180 \text { degrees without much further erosion. }\end{array}$ \\
\hline 25 & 100 & 0.8 & 6 & & $5 \%$ & 2 & 1 & packed snow & One side of the remaining mat disintegrated without spray. \\
\hline 26 & 100 & 0.8 & & 4 & $0 \%$ & & & & The filter frame is completely empty. \\
\hline
\end{tabular}

- KEY 5 Full strength, rubbing between fingers fill not disintegrate fibers into paste.

4 Vigorous rubbing will disintegrate some of the fibers into paste.

3 Moderate rubbing will disintegrate most of the fibers into paste.

2 Slight rubbing will disintegrate all the fibers into paste.

1 No mechanical strength, any slight disturbance breaks dowa the material.

$\begin{array}{ll}5 & \text { Completely fibrous } \\ 4 & \text { Mostly fibrous, slightly digested } \\ 3 & \text { Partly fibrous, partly digested } \\ 2 & \text { Slightly fibrous, mostly digested } \\ 1 & \text { Completely digested }\end{array}$




\begin{tabular}{|c|c|c|c|c|c|c|c|c|c|}
\hline 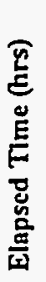 & 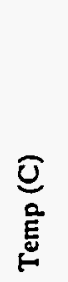 & 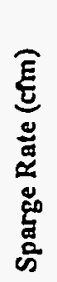 & 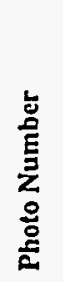 & 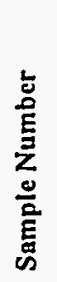 & 䓌 & 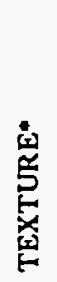 & 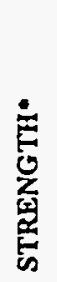 & 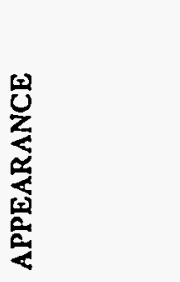 & REMARKS \\
\hline 0 & 24 & 0.8 & & & $100 \%$ & 5 & 5 & cotton gauze & Immersed filter. Began beating and sparglng. \\
\hline 4 & 100 & 0.8 & & & & & & & Sprayed $1 \mathrm{~min}$ ( 4 nozzles at 90 degrees) at $3 \mathrm{gpm}$. No erosion. \\
\hline 8 & 100 & 0.8 & & & & & & & Sprayed 1 minute at $3 \mathrm{gpm}$. No erosion noted. \\
\hline 12 & 100 & 0.8 & 1 & 1 & $100 \%$ & 4 & 4 & cotton gauze & Sprayed 1 minute at $3 \mathrm{gpm}$. No eroston noted. \\
\hline \multicolumn{10}{|c|}{6 HOUR SOAKING PERIOD, NO HEATING, NO SPARGING } \\
\hline 18 & 65 & 0.8 & 2 & & & & & & \\
\hline 22 & 100 & 0.8 & 3,4 & 2 & $100 \%$ & 4 & 3 & cotton gauze & Sprayed 1 minute at $3 \mathrm{gpm}$. No erosion noted. \\
\hline 26 & 100 & 0.8 & & & & & & & Sprayed 1 minute at $3 \mathrm{gpm}$. Minor erosion noted. \\
\hline 30 & 100 & 0.8 & 5 & & $75 \%$ & 3 & 2 & cotton gauze & Sprajed 1 minute at $3 \mathrm{gpm}$. Significant erosion noted. \\
\hline 34 & 100 & 0.8 & 6 & & $55 \%$ & 2 & 1 & packed snow & Sprayed 1 minute at $3 \mathrm{gpm}$. Some eroded completely through. \\
\hline 38 & 100 & 0.8 & 7,8 & & $10 \%$ & 1 & 1 & packed snow & Sprayed 1 minute at $3 \mathrm{gpm}$. Neariy all gone. \\
\hline 41 & 100 & 0.8 & & & $0 \%$ & & & & The filter frame is completely empty witbout additional spray. \\
\hline
\end{tabular}

*KEY

5 Full strength, rubbing between fingers fill not disintegrate fibers lato paste.

4 Vigorous rubbing will disintegrate some of the fibers into paste.

3 Moderate rubbing will disintegrate most of the fibers into paste.

2 Slight rubbing will disintegrate all the fibers into paste.

1 No mechanical strength, any slight disturbance breaks dowo the material.

$\begin{array}{ll}5 & \text { Completely fibrous } \\ 4 & \text { Mostly fibrous, slightly digested } \\ 3 & \text { Partly fibrous, partly digested } \\ 2 & \text { Slightly fibrous, mostly digested } \\ 1 & \text { Completely digested }\end{array}$




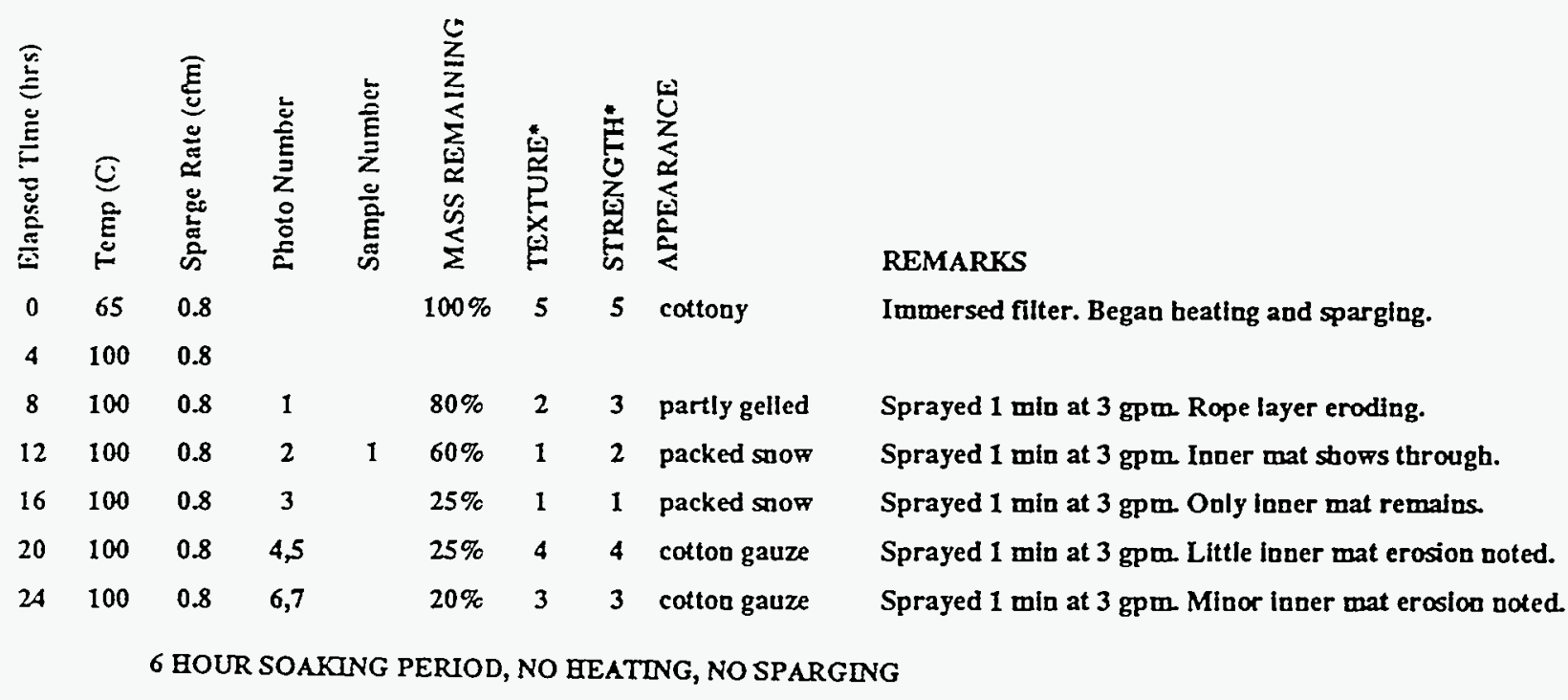

$\begin{array}{ccccccccl}30 & 100 & 0.8 & 8 & 15 \% & 2 & 2 & \text { packed snow } & \text { Sprayed } 1 \text { min at } 3 \text { gpm. Inner mat eroding. } \\ 34 & 100 & 0.8 & 9-12 & 2 \% & 1 & 1 & \text { packed snow } & \text { Sprayed } 3 \text { min at } 3 \text { gpm. Steady erosion noted. } \\ 35 & 100 & 0.8 & & 0 \% & & & & \text { The last } 2 \% \text { washed out without additional spray. }\end{array}$

* KEY 5 Full strength, rubbing between fingers will not disintegrate fibers into paste.

4 Vigorous rubbing will disintegrate some of the fibers into paste.

3 Moderate rubbing will disintegrate most of the fibers into paste.

2 Sligbt rubbing will disintegrate all the fibers into paste.

1 No mechanical strength, any slight disturbance breaks dowa the material.

$\begin{array}{ll}5 & \text { Completely fibrous } \\ 4 & \text { Mostly fibrous, slightly digested } \\ 3 & \text { Partly fibrous, partly digested } \\ 2 & \text { Slightly fibrous, mostly digested } \\ 1 & \text { Completely digested }\end{array}$




\begin{tabular}{|c|c|c|c|c|c|c|c|c|c|}
\hline 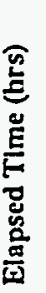 & $\begin{array}{l}\underset{\mathcal{O}}{\mathrm{O}} \\
\stackrel{\mathrm{E}}{\mathrm{E}} \\
\stackrel{\mathrm{E}}{\mathrm{E}}\end{array}$ & 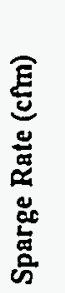 & 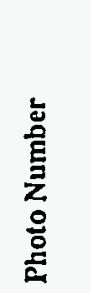 & 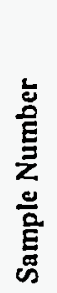 & 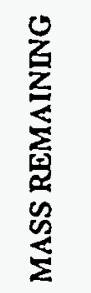 & 兽 & 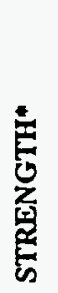 & 歹 & REMARKS \\
\hline $\mathbf{0}$ & 100 & 0.8 & 1 & & $100 \%$ & 5 & 5 & cottony & Immersed fitter In heated solution. Began sparging. \\
\hline 4 & 100 & 0.8 & 2,3 & & $95 \%$ & 4 & 4 & wet cotton & Sprayed 1 min at $3 \mathrm{gpm}$ No erosion noted. \\
\hline 8 & 100 & 0.8 & 4,5 & & $90 \%$ & 2 & 3 & partly gelled & Sprayed 1 min at $3 \mathrm{gpm}$. Some erosion noted. \\
\hline \multicolumn{10}{|c|}{6 HOUR SOAKING PERIOD, NO HEATING, NO SPARGING } \\
\hline 14 & 50 & 0.8 & 6 & & $80 \%$ & 2 & 2 & packed soow & Sprayed 1 min at $3 \mathrm{gpm}$. More erosion noted. \\
\hline 18 & 100 & 0.8 & 7,8 & & $40 \%$ & 2 & 1 & packed soow & Sprayed 1 min at $3 \mathrm{gpm}$. Inner mat shows through. \\
\hline 22 & 100 & 0.8 & 9,10 & & $25 \%$ & 1 & 1 & packed snow & Sprayed 1 min at 3 gpm. Only inner mat remains. \\
\hline 26 & 100 & 0.8 & 11,12 & & $25 \%$ & 3 & 3 & cotton gauze & Sprayed 1 min at $3 \mathrm{gpm}$. Little inner mat erosion noted. \\
\hline \multicolumn{10}{|c|}{14 HOUR SOAKING PERIOD, NO BEATING, NO SPARGING } \\
\hline 40 & 44 & 0.8 & 13,14 & & $20 \%$ & 2 & 2 & packed soow & Sprayed 1 min at $3 \mathrm{gpm}$. Inner mat eroding. \\
\hline 43 & 42 & 0.8 & 15 & & $15 \%$ & 2 & 2 & packed suow & $\begin{array}{l}\text { Sprayed } 2 \text { min at } 3 \mathrm{gpm} \text {. Only minor erosion noted. More } \\
\text { heating needed for further digestion. }\end{array}$ \\
\hline 45 & 100 & 0.8 & 16,17 & 1 & $5 \%$ & 2 & 1 & packed snow & min spray at 3 gpm. \\
\hline 47 & 100 & 0.8 & $18-20$ & 2 & $0 \%$ & & & & Sprayed 2 min at $3 \mathrm{gpm}$, leaving the filter frame empty. \\
\hline
\end{tabular}

*KEY 5 Full strength, rubbing between fingers will not disintegrate fibers into paste.

4 Vigorous rubbing will disintegrate some of the fibers Into paste.

3 Moderate rubbing will disintegrate most of the fibers Into paste.

2 Slight rubbing will disintegrate all the fibers into paste.

1 No mechanical strength, any slight disturbance breaks down the material.

5 Completely fibrous

4 Mostly fibrous, slightly digested

3 Partly fibrous, partly digested

2 Slightly fibrous, mostly digested

1 Completely digested 


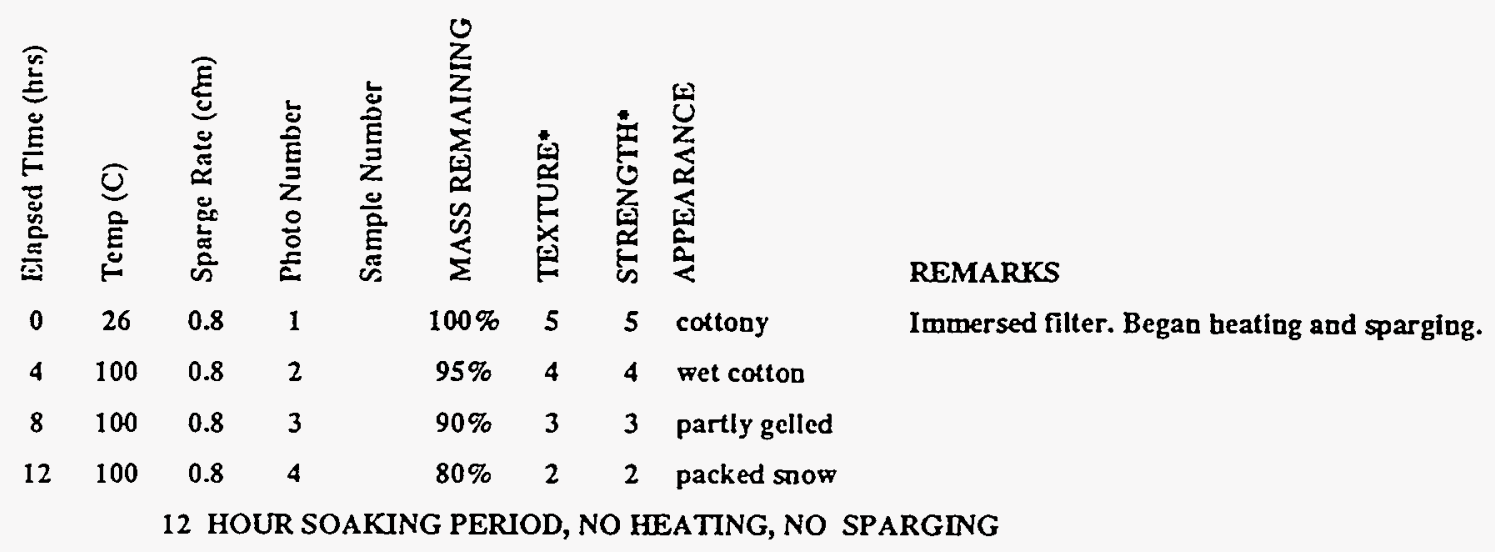

$\begin{array}{ccccccccc}24 & 100 & 0.8 & 5,6 & 25 \% & 2 & 2 & \text { packed soow } & \text { Sprayed } 4 \text { min at } 3 \text { gpm. Only inner mat remains. } \\ 28 & 100 & 0.8 & 7 & 25 \% & 3 & 4 & \text { cotton gauze } & \\ 32 & 100 & 0.8 & 8 & 15 \% & 2 & 2 & \text { packed soow } & \\ 36 & 100 & 0.8 & & 0 \% & & & & \text { Filter frame is empty without additional spraying. }\end{array}$

* KEY 5 Full strength, rubbing between fingers will not disintegrate fibers into paste.

4 Vigorous rubbing will disintegrate some of the fibers into paste.

3 Moderate rubbing will disintegrate most of the fibers into paste.

2 Slight rubbing fill disintegrate all the fibers loto paste.

1 No mecbanical strength, any slight disturbance breaks down the material.

5 Completely fibrous

4 Mostly fibrous, slightly digested

3 Partly fibrous, partly digested

2 Slightly fibrous, mostly digested

1 Completely digested 


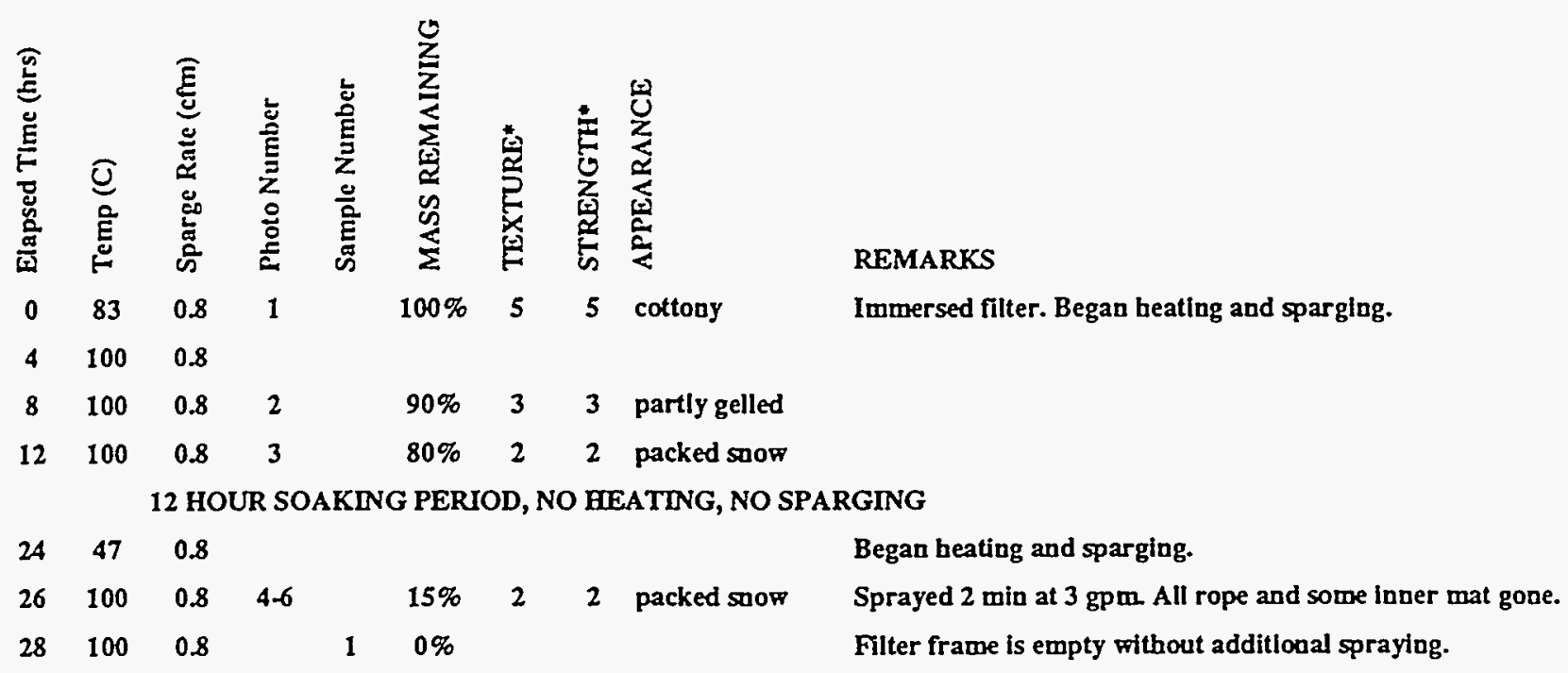

-KEY 5 Full strength, rubbing between fingers will not disintegrate fibers into paste.

4 Vigorous rubbing will disintegrate some of the fibers Into paste.

3 Moderate rubbing will disintegrate most of the fibers into paste.

2 Slight rubbing will disintegrate all the fibers into paste.

1 No mechanical strength, any slight disturbance breaks down the material.

$\begin{array}{ll}5 & \text { Completely fibrous } \\ 4 & \text { Mostly fibrous, slightly digested } \\ 3 & \text { Partly fibrous, partly digested } \\ 2 & \text { Sligbtly fibrous, mostly digested } \\ 1 & \text { Completely digested }\end{array}$




\begin{tabular}{|c|c|c|c|c|c|c|c|c|}
\hline 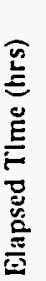 & $\begin{array}{l}\underset{Q}{E} \\
\stackrel{0}{E} \\
E\end{array}$ & 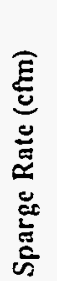 & 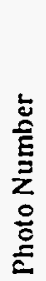 & 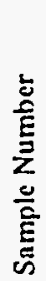 & 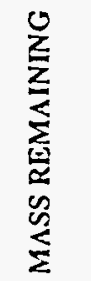 & 甞 & 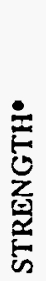 & 㝵 \\
\hline 0 & & 0.8 & & & $100 \%$ & 5 & 5 & cottony \\
\hline 4 & 100 & 0.8 & 1 & & $95 \%$ & 4 & 4 & wet cotton \\
\hline 8 & 100 & 0.8 & 2 & & $90 \%$ & 3 & 3 & partly gelled \\
\hline 12 & 100 & 0.8 & 3 & & $80 \%$ & 2 & 2 & packed snow \\
\hline 16 & 100 & 0.8 & 4 & & $75 \%$ & 1 & 1 & packed snow \\
\hline 20 & 100 & 0.8 & 5 & & $0 \%$ & & & \\
\hline
\end{tabular}

\section{REMARKS}

Immersed filter. Began heating and sparging.

Filter frame is completely empty without any spraying.

*KEY

5 Full strength, rubbing between fingers will not disintegrate fibers into paste.

4 Vigorous rubbing will disintegrate some of the fibers into paste.

3 Moderate rubbing will disintegrate most of the fibers into paste.

2 Slight rubbing will disintegrate all the fibers into paste.

1 No mechanical strength, any slight disturbance breaks down the material.

$5 \quad$ Completely fibrous

4 Mostly fibrous, slightly digested

3 Partly fibrous, partly digested

$2 \quad$ Slightly fibrous, mostly digested

1 Completely digested 


\begin{tabular}{|c|c|c|c|c|c|c|c|c|c|}
\hline 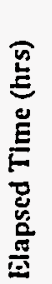 & 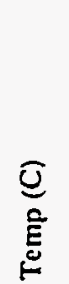 & 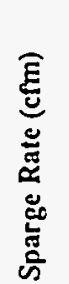 & 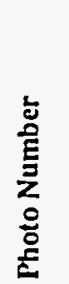 & 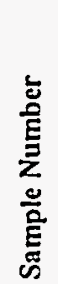 & 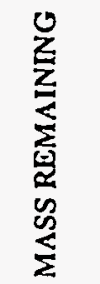 & 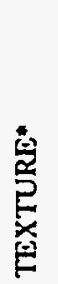 & 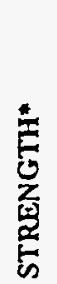 & 惢 & REMARKS \\
\hline $\mathbf{0}$ & & 0.8 & & & $100 \%$ & 5 & 5 & cottony & Immersed filter. Began heating and sparging. \\
\hline 4 & 100 & 0.8 & 1 & & $95 \%$ & 4 & 4 & wet cotton & \\
\hline 8 & 100 & 0.8 & 2 & & $90 \%$ & 3 & 3 & partly gelled & \\
\hline 12 & 100 & 0.8 & 3 & & $85 \%$ & 2 & 2 & packed snow & \\
\hline 16 & 100 & 0.8 & 4 & & $80 \%$ & 1 & 1 & packed snow & \\
\hline 20 & 100 & 0.8 & 5 & & $75 \%$ & 1 & 1 & packed snow & \\
\hline 24 & 100 & 0.8 & $6-8$ & & $25 \%$ & 2 & 2 & packed soow & Sprayed 2 min at $3 \mathrm{gpm}$. All rope and some inner mat gone. \\
\hline 28 & 100 & 0.8 & 9 & & $20 \%$ & 1 & 1 & packed snow & \\
\hline 30 & 100 & 0.8 & 10 & & $0 \%$ & & & & Filter frame is completely empty without additional spraying \\
\hline
\end{tabular}

*KEY. 5 Full strength, rubbing between fingers will not disintegrate fibers into paste.

4 Vigorous rubbing pill disintegrate some of the fibers into paste.

3 Moderate rubbing will disintegrate most of the fibers into paste.

2 Slight rubbing will disintegrate all the fibers into paste.

1 No mechanical strength, any slight disturbance breaks down the material.

$5 \quad$ Completely fibrous

$4 \quad$ Mostly fibrous, slightly digested

3 Partly fibrous, partly digested

2 Slightly fibrous, mostly digested

1 Completely digested 